\title{
Deciduous dentition and dental eruption of Hyainailouroidea (Hyaenodonta, "Creodonta," Placentalia, Mammalia)
}

\author{
Matthew R. Borths and Nancy J. Stevens
}

\begin{abstract}
Deciduous dental morphology and the sequence of permanent dental eruption offer developmental and phylogenetic insights into mammalian evolution. Early life history in Hyaenodonta, a morphologically diverse and biogeographically widespread clade of carnivorous mammals known from the Paleogene and early Neogene, has only been examined closely in one genus: Hyaenodon. Here we describe the deciduous dental morphology for six hyainailouroids, a clade of hyaenodonts distantly related to Hyaenodon that dominated early Cenozoic meat-eating niches of Afro-Arabia for nearly $20 \mathrm{Ma}$. Results suggest significant variation among hyainailouroids in expression of the $\mathrm{dP}^{3}$ and $\mathrm{dP}^{4}$ protocone, paracone, and metacone and in expression of the $\mathrm{dP}_{3}$ and $\mathrm{dP}_{4}$ paraconid, metaconid, and talonid. Deciduous dental characters were incorporated into a Bayesian phylogenetic analysis. The topology was congruent with earlier systematic examinations of hyaenodont evolution, suggesting that deciduous dental features can be phylogenetically informative and that taxa known only from deciduous teeth can be incorporated into studies of mammalian systematics. Based on the specimens described herein, the dental eruption sequence of Hyainailouroidea is reconstructed. $\mathrm{P}^{4}$ and $\mathrm{P}^{3}$ erupt after $\mathrm{M}^{3}$, evidence that the deciduous carnassial complex formed between $\mathrm{dP}^{3}$ and $\mathrm{dP}_{4}$ was retained until late in development, permitting hyaenodonts to heavily wear shearing blades on these teeth before replacement. This differs from Carnivora, a group that tends to replace deciduous dentition earlier in development, effectively limiting carnivorans to a single set of carnassials throughout most of their lifespan. This developmental difference between carnivorans and hyaenodonts can now be examined in a larger systematic and ecological context.
\end{abstract}

Matthew R. Borths. Department of Biomedical Sciences, Heritage College of Osteopathic Medicine, Ohio University, Athens, Ohio 45701, USA; Center for Ecology and Evolutionary Studies, Ohio University, Athens, Ohio 45701, USA. borths.1@gmail.com Nancy J. Stevens. Department of Biomedical Sciences, Heritage College of Osteopathic Medicine, Ohio University, Athens, Ohio 45701, USA; Center for Ecology and Evolutionary Studies, Ohio University, Athens, Ohio 45701, USA. stevensn@ohio.edu

Borths, Matthew R. and Stevens, Nancy J. 2017. Deciduous dentition and dental eruption of Hyainailouroidea (Hyaenodonta, "Creodonta," Placentalia, Mammalia). Palaeontologia Electronica 20.3.55A: 1-34. https://doi.org/10.26879/776 palaeo-electronica.org/content/2017/2056-deciduous-hyaenodont-teeth 
Borths \& SteVENS: Deciduous hyAENOdONT TEETH

Keywords: Ontogeny; Carnivory; Egypt; Africa; Paleogene

Submission: 26 April 2017 Acceptance: 31 October 2017

\section{INTRODUCTION}

Fossilized remains of animals are often interpreted by paleontologists as phenotypes shaped by natural selection (e.g., Stern and Susman, 1983; Shubin et al., 2006; Tseng et al., 2016), with hypotheses surrounding adaptation, niche occupation, evolution, and extinction of a species typically examined through the lens of the adult phenotype (e.g., Ross, 1996; Finarelli and Flynn, 2009; Goswami and Polly, 2010). Yet examination of extant organisms demonstrates that natural selection acts throughout the life cycle, and fitness is significantly impacted by developmental stages that precede maturity (Lindström, 1999). Hence the adaptive strategies employed by a species or lineage can only truly be understood through deeper knowledge of the ontogeny of a species or lineage (Sánchez-Villagra, 2010a; Codron et al., 2013; Urdy et al., 2013; Hone et al., 2016). As a heritable aspect of an animal's biology, developmental data is also a rich source of phylogenetic information, providing insight into evolutionary relationships (e.g., de Queiroz, 1985; Smith, 2000; Asher and Lehmann, 2008).

In mammals, the reduction of dental replacement to diphyodonty has built a readily preserved ontogenetic calibration point into the mouths of most taxa (Anders et al., 2011). The replacement of deciduous teeth, eruption of adult dentition, and subsequent wear contribute information on the rate of maturation across lineages (e.g., Slaughter et al., 1974, Smith, 2000; Asher and Lehmann, 2008; Ciancio et al., 2012; Veitschegger and SánchezVillagra, 2016). Dental eruption sequences can be compared with other proxies for developmental maturity, such as long bone epiphyseal fusion (Coutinho et al., 1993; Uhen, 2000) and cranial suture fusion (Sánchez-Villagra, 2010b; Rager et al., 2013), to identify key developmental phases in extinct taxa that can be used to reconstruct life histories and phylogenetic relationships (Fink, 1982; Smith, 1989; O'Leary et al., 2013).

Hyaenodonta is a diverse radiation of carnivorous placental mammals found in terrestrial ecosystems in Eurasia, North America, and AfroArabia throughout the Paleogene (Rose, 2006). The clade persisted into the Neogene in Asia and
Afro-Arabia, making it the longest-lived radiation of meat-eating placental mammals besides Carnivora (Lewis and Morlo, 2010). Parsing out the evolution, life history, and extinction of Hyaenodonta is critical for building a larger understanding of the evolution of the niches occupied by modern carnivorous mammals. Previous work on the dental development of hyaenodonts focused on the genus Hyaenodon, a genus from the Eurasian and North American clade Hyaenodontinae (Mellet, 1977; Bastl et al., 2011; Bastl and Nagel, 2013; Bastl et al., 2014); deciduous dental materials preserved in other hyaenodonts (e.g., Lesmesodon, Cynohyaenodon, Paroxyaena) have received somewhat less attention (but see Morlo and Habersetzer, 1999; Lavrov, 2007). Recent systematic research demonstrates that Hyaenodon is only distantly related to Hyainailouroidea, a separate hyaenodont clade that contains hypercarnivorous taxa and all AfroArabian hyaenodonts (Rana et al., 2015; Borths et al., 2016). But only a few deciduous teeth have been described from Afro-Arabian hyaenodonts (Morales et al., 2010; Solé et al., 2016), making it difficult to compare the life histories of Afro-Arabian hyainailouroids to Eurasian and North American hyaenodont lineages and to use deciduous dental morphology and dental eruption to probe phylogenetic relationships among key taxa in this important group of early Cenozoic predators.

In this study, we describe and refer hyaenodont deciduous dental specimens from the late Eocene-early Oligocene (Fayum Depression, Egypt) and the early Miocene (Rusinga Island and Fort Ternan, Kenya) to five known hyainailouroid genera: Apterodon, Leakitherium, Anasinopa, Dissopsalis, Masrasector, and Metasinopa. We compare the new deciduous dental material to Eurasian and North American hyaenodont materials to reconstruct dental development patterns among hyainailouroids. Building upon the efforts of Bastl et al. (2014), we incorporate this new morphological information into a phylogenetic analysis that includes deciduous dental characters. Finally, we use morphological and developmental data preserved in these specimens to discuss how hyaenodont dental development informs our understanding of life history strategies in the clade. 


\section{MATERIALS AND DESCRIPTIVE METHODS}

\section{Permissions}

Specimens bearing DPC reference numbers described herein are available at the Division of Fossil Primates at the Duke Primate Center in Raleigh, NC and were collected and exported with permission granted by the Egyptian Mineral Resources Authority (formerly the Egyptian Geological Survey and Minding Authority) and the Egyptian Geological Museum. Specimens bearing KNM reference numbers described herein are available at the Nairobi National Museum, part of the National Museums of Kenya, and were examined under research permits issued by the Kenyan National Commission for Science, Technology and Innovation and as research affiliates of the National Museums of Kenya.

\section{Institutional Abbreviations}

$\mathrm{BMNH}$, Natural History Museum, London; DPC, Duke Lemur Center, Division of Fossil Primates, Duke University, Durham, NC; KNM, National Museums of Kenya, Nairobi.

\section{Morphological Measurements and Nomenclature}

Dental measurements were collected from digital photographs of the specimens using ImageJ (Schneider et al., 2012). Dental nomenclature and measurement definitions follow Borths et al. (2016) and Holroyd (1999).

\section{CT Scanning and Rendering}

The $\mu$-CT scans of DPC specimens were collected at the Duke University Shared Materials Instrumentation Facility using a Nikon XTH 225 ST scanner following the protocol described in Miller et al. (2017). Surface models and figures illustrating developing dentition were constructed using Avizo 7.0. Digital models of all scanned specimens are available at Morphosource (Project P393) (www.morphosource.org).

\section{SYSTEMATIC PALEONTOLOGY}

Class MAMMALIA Linnaeus, 1758

Order HYAENODONTA Van Valen, 1967 sensu

Solé et al., 2015

Superfamily HYAINAILOUROIDEA Borths, Holroyd, and Seiffert, 2016

Subfamily APTERODONTINAE Szalay, 1967

Genus APTERODON Fischer, 1880

Type species. Apterodon gaudryi Fischer, 1880.
Other included species. Apterodon altidens Schlosser, 1910; Apterodon intermedius LangeBadré and Böhme, 2005; Apterodon langebadreae Grohé et al., 2012; Apterodon macrognathus Andrews, 1904; Apterodon saghensis Simons and Gingerich, 1974.

\section{Apterodon macrognathus Andrews, 1904}

Figures 1-2, Tables 1-2

Referred specimens. DPC 4126, right maxilla fragment with $\mathrm{dP}^{4}$ (Fayum Depression, Jebel Qatrani Formation, Quarry M); DPC 8217, left dentary fragment with $\mathrm{dP}_{3}, \mathrm{dP}_{4}, \mathrm{M}_{1}$ (Fayum Depression, Jebel Qatrani Formation, Quarry M). Note: These specimens were not found in association.

\section{Description}

In the maxilla of Apterodon macrognathus (DPC 4126; Figure 1) the infraorbital foramen is superior and slightly anterior to the mesial root of $\mathrm{dP}^{4}$. The parastyle is mesiodistally short and divided by a buccolingually compressed ridge that continues the preparacrista onto the parastyle. The tall paracone is crenulated and buccolingually compressed and rises to an acute, slightly distallydirected peak. The metacone is individuated from the paracone and rises over half the height of the paracone after the cusps diverge. The mesiodistal length of the paracone base is subequal to the mesiodistal length of the metacone. The metacone forms a distinct carnassial notch with the buccolingually compressed and mesiodistally short metastyle. The metastyle rises to a distinct apex that is approximately one-third the height of the metacone. The buccal margin of the tooth is traced by a distinct, beaded buccal cingulum that connects the parastyle to the metastyle, dipping ventrally at the distobuccal face of the paracone. The protocone is mesiodistally broad. The lingual point of the protocone is a distinct cusp that projects to the same height as the apex of the metastyle. The trigon basin is deep and defined by a wide lingual cingulum. The alveoli of $\mathrm{dP}^{3}$ are also preserved, indicating the root that supported the protocone of $\mathrm{dP}^{3}$ was closely packed with the distal root of $\mathrm{dP}^{3}$.

In the dentary of Apterodon macrognathus (DPC 8217, Figure 2) $\mathrm{dP}_{3}$ is a buccolingually compressed tooth with a prominent protoconid and small, but distinct talonid. The preprotocristid curves distally to the apex of the protoconid. The postprotocristid slopes more gently to the cristid obliqua. The entoconid is a prominent, sectorial cusp along the buccal margin of the talonid. Distinct buccal and lingual cingula rim the entire dou- 


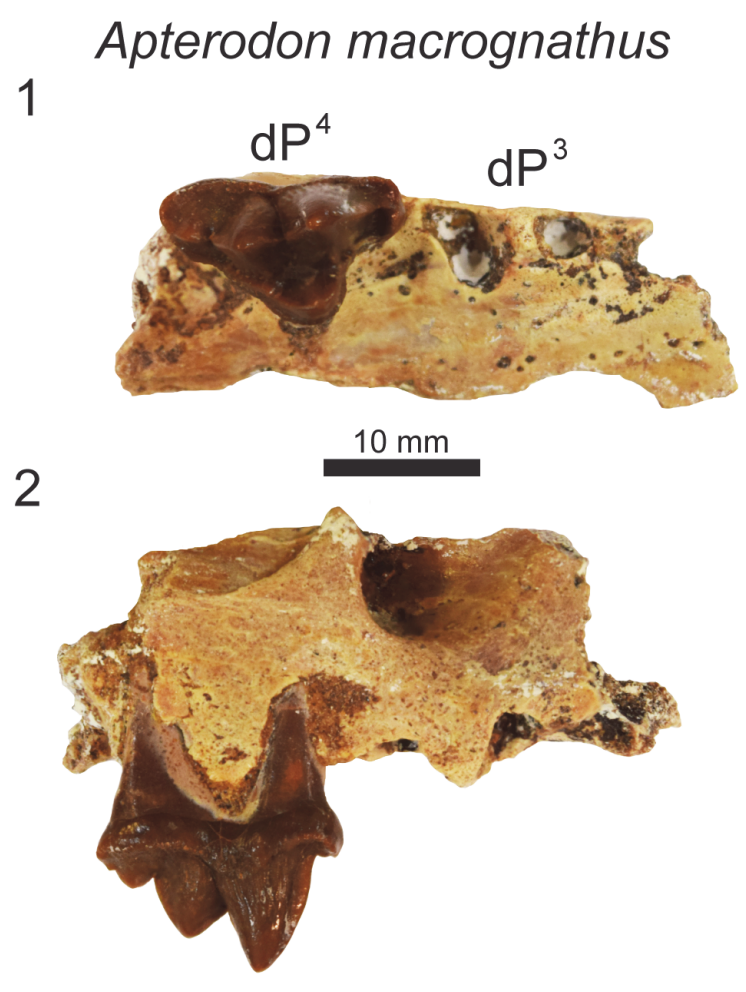

3

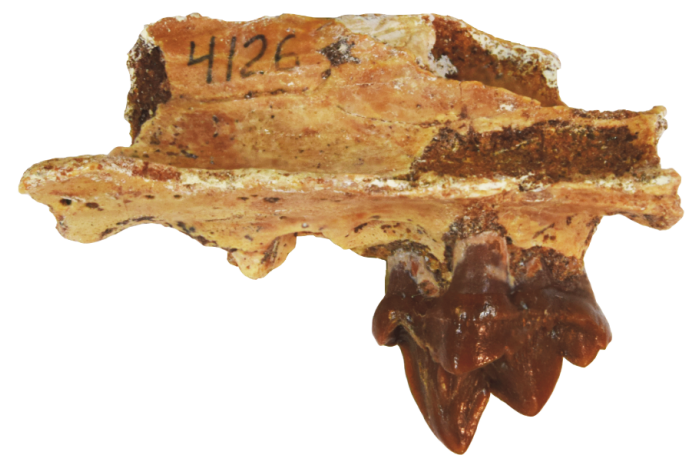

FIGURE 1. Apterodon macrognathus left maxilla fragment with $\mathrm{dP}^{4}$ and alveoli of $\mathrm{dP}^{3}$ (DPC 4126) from Quarry M (early Oligocene) in the Fayum Depression, Egypt in 1) occlusal view; 2) buccal view; and 3) lingual view. Scale bar is $10 \mathrm{~mm}$.

ble-rooted tooth. A mesiodistally elongate protoconid dominates the outline of $\mathrm{dP}_{4}$. The paraconid is low and mesiodistally short. The carnassial notch dives to the same level as the cristid obliqua. As on $\mathrm{dP}_{3}$, the protoconid points slightly distally. The pre- and postprotocristid are buccolingually compressed and blade-like. The postprotocristid forms a deep notch at the cristid obliqua. The entoconid rises from the notch to a point taller than the paraconid and nearly half the height of the protoconid. There is no indication of a metaconid on
$\mathrm{dP}_{4}$. The $\mu-C T$ of the dentary of Apterodon macrognathus (Figure 2) indicates the protoconid of $\mathrm{M}_{2}$ was formed before the germs of either $\mathrm{P}_{4}$ or $\mathrm{P}_{3}$ began to coalesce.

\section{Remarks}

Apterodontines combine a key morphological feature of hypercarnivores, the reduction or absence of metaconids on the lower molars, with features of more generalist carnivores such as well-developed talonids on the lower molars, divergent metacones and paracones, and mesiodistally abbreviated metastyles on the upper molars (Van Valkenburgh, 2007) complicating dietary and phylogenetic inferences (Van Valen 1966; Szalay, 1967; Grohé et al., 2012). Recent phylogenetic studies (Borths et al., 2016; Borths and Seiffert, 2017) incorporate morphological features of the cranial vault (Solé et al., 2015), suggesting Apterodontinae as the sister clade of Hyainailourinae. Like the hyainailourines Paroxyaena and Leakitherium, the $\mathrm{dP}^{4}$ of Apterodon macrognathus (Figure 1) exhibits a buccolingually compressed paracone that is distally directed. A. macrognathus also shares with Leakitherium and Paroxyaena a mesiodistally short metastyle on $\mathrm{dP}^{4}$, crenulated enamel, and a lobe-like protocone. In contrast, the $\mathrm{dP}^{4}$ of the teratodontines Metasinopa and Masrasector exhibit extensive metastyles, smooth and thin enamel, and buccolingually narrow protocones, morphology shared with Pakakali, a hyaenodont from the late Oligocene of the Rukwa Rift Basin (Borths and Stevens, 2017). These observations, in conjunction with the phylogenetic analysis conducted here to test the utility of deciduous dental characters, support the close relationship between Apterodontines and Hyainailourines in the clade Hyainailouridae.

Family HYAINAILOURIDAE Pilgrim, 1932 sensu Borths et al., 2016

Subfamily HYAINAILOURINAE Pilgrim, 1932 Genus LEAKITHERIUM Savage, 1965

Type and only species. Leakitherium hiwegi Savage, 1965.

\section{Leakitherium hiwegi Savage, 1965}

Figure 3, Tables 1-2

Referred specimens. KNM-RU 2949, left maxilla fragment with $\mathrm{dP}^{3}$ and $\mathrm{dP}^{4}$ (CMF 4025 in Savage, 1965; Rusinga Island, Kenya); KNM-RU 15182, maxilla fragment with $\mathrm{dP}^{3}, \mathrm{dP}^{4}, \mathrm{P}^{4}$ in crypt (Rusinga Island, Kenya). 
1

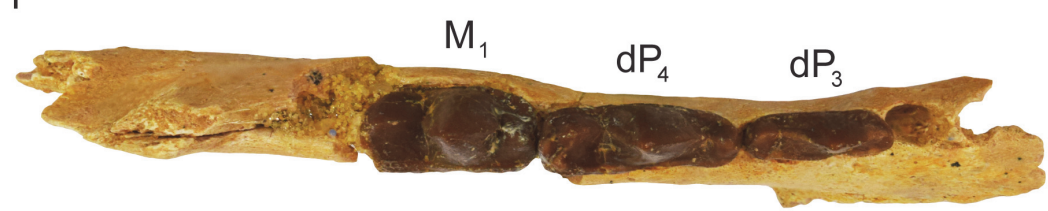

2
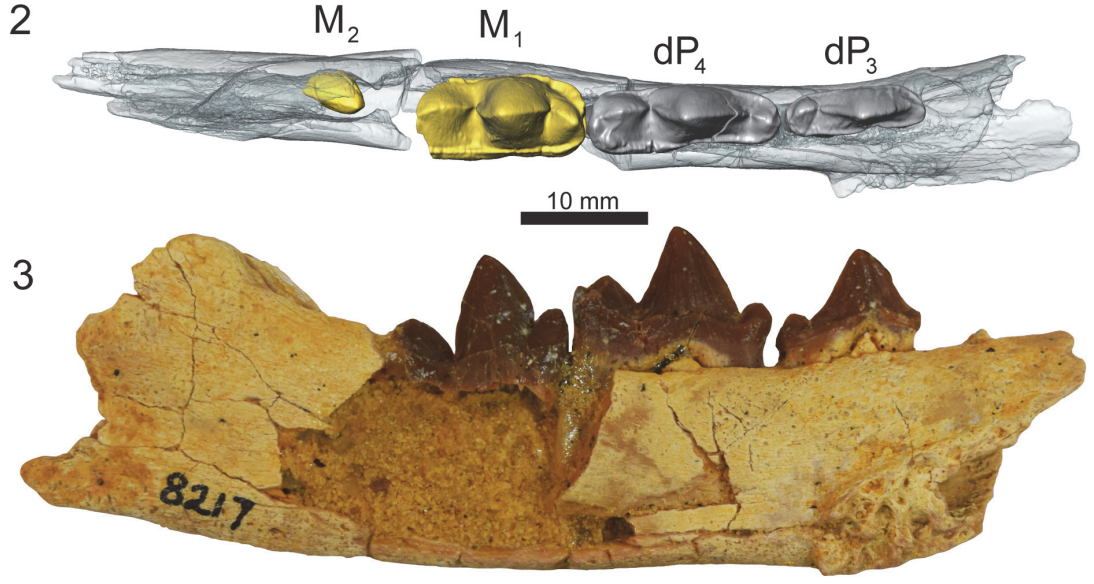

4

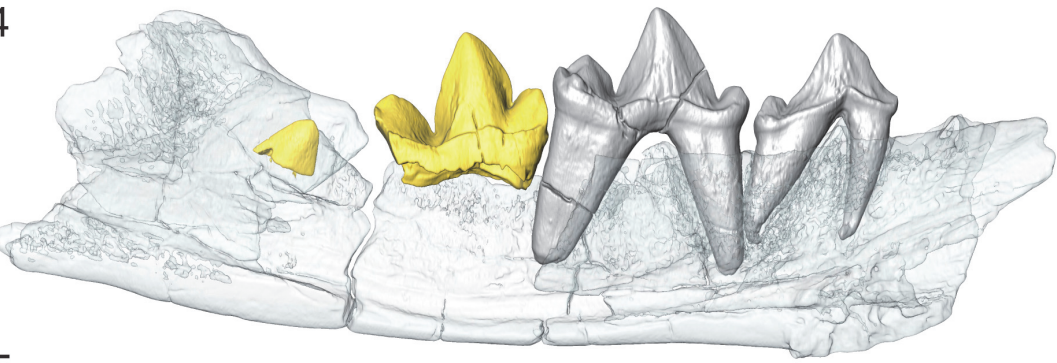

5

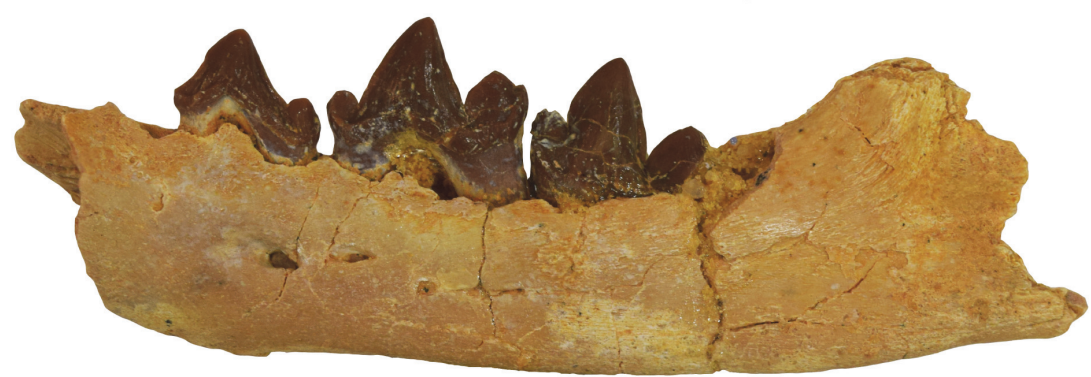

6

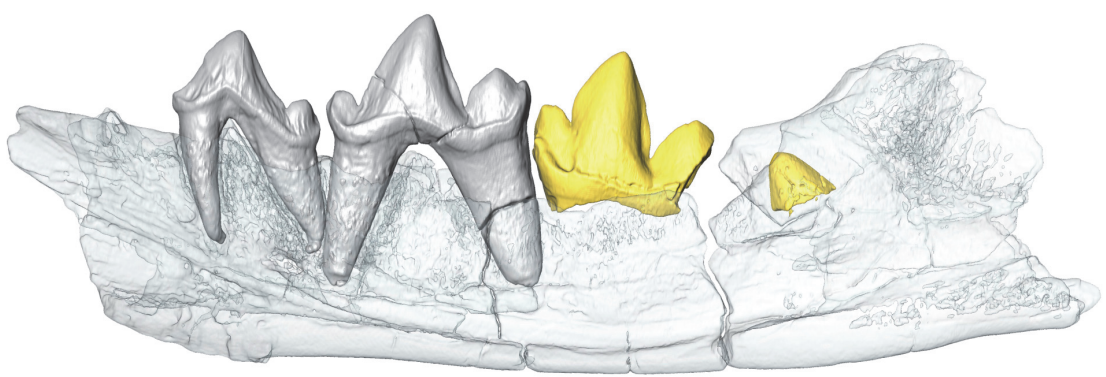

FIGURE 2. Apterodon macrognathus left dentary with $\mathrm{dP}_{3}, \mathrm{dP}_{4}, \mathrm{M}_{1}$ and $\mathrm{M}_{2}$ in crypt (DPC 8217) from Quarry $\mathrm{M}$ (early Oligocene) in the Fayum Depression, Egypt. Original specimen figured with digital model based on $\mu$-CT scans reconstructed in Avizo. Mandibular corpus rendered transparent to reveal developing dentition. Grey, deciduous dentition. Yellow, permanent dentition. 1) Specimen occlusal view; 2) model occlusal view; 3) specimen lingual view; 4) model lingual view; 5) specimen buccal view; 6) model buccal view. Scale bar is $10 \mathrm{~mm}$. 
TABLE 1. Measurements of the upper dentition. Asterisk indicates the measurements are based on the alveoli of the tooth. Length is mesiodistal length. Width is buccolingual length. , indicates an approximate measurement based on fragmentary material. See methods for definitions of these measurements.

\begin{tabular}{|c|c|c|c|c|}
\hline Taxon & Specimen & Tooth & Length & Width \\
\hline \multirow[t]{2}{*}{ Apterodon macrognathus } & DPC 4126 & $\mathrm{dP}^{3 *}$ & 10.8 & 4.9 \\
\hline & & $\mathrm{dP}^{4}$ & 15.6 & 9.0 \\
\hline \multirow[t]{2}{*}{ Leakitherium hiwegi } & KNM-RU 2949 & $\mathrm{dP}^{3}$ & 15.4 & 10.8 \\
\hline & & $\mathrm{dP}^{4}$ & 16.7 & 13.4 \\
\hline \multirow[t]{2}{*}{ Leakitherium hiwegi } & KNM-RU 15182 & $\mathrm{dP}^{3}$ & 15.2 & 14.0 \\
\hline & & $\mathrm{dP}^{4}$ & $\sim 16.5$ & 17.5 \\
\hline \multirow[t]{3}{*}{ Anasinopa leakeyi } & KNM-RU 2385 & $\mathrm{dP}^{2}$ & 9.0 & 3.7 \\
\hline & & $\mathrm{dP}^{3}$ & 9.6 & 6.7 \\
\hline & & $\mathrm{dP}^{4}$ & 10.2 & 9.2 \\
\hline \multirow[t]{3}{*}{ Dissopsalis pyroclasticus } & KNM-FT 3357 & $\mathrm{dP}^{3}$ & 15.4 & 9.2 \\
\hline & & $\mathrm{dP}^{4}$ & 15.6 & 13.4 \\
\hline & & $M^{1 *}$ & 15.5 & 16.0 \\
\hline \multirow[t]{2}{*}{ Masrasector nananubis } & DPC 20882 & $\mathrm{dP}^{3}$ & 4.8 & $\sim 3.0$ \\
\hline & & $\mathrm{dP}^{4}$ & 4.4 & 2.7 \\
\hline \multirow[t]{3}{*}{ Masrasector nananubis } & DPC 13837 & $\mathrm{dP}^{3}$ & 5.0 & 3.0 \\
\hline & & $\mathrm{dP}^{4}$ & 5.0 & 3.4 \\
\hline & & $\mathrm{M}^{1}$ & 5.7 & 4.5 \\
\hline \multirow[t]{3}{*}{ Metasinopa sp. } & DPC 10199 & $\mathrm{dP}^{3}$ & 10.5 & 5.1 \\
\hline & & $\mathrm{dP}^{4}$ & 10.9 & 7.1 \\
\hline & & $M^{1}$ & 12.5 & 11.7 \\
\hline
\end{tabular}

\section{Description}

KNM-RU 2949, a maxilla fragment of Leakitherium hiwegi (Figure 3), preserves the crowns of both $\mathrm{dP}^{3}$ and $\mathrm{dP}^{4}$. This specimen was originally numbered CMF 4025 and was briefly described and illustrated by Savage (1965) as $\mathrm{P}^{4}$ and $\mathrm{M}^{1}$ and designated as the paratype of Leakitherium. Though the infraorbital foramen is not preserved intact, the floor of the infraorbital canal traces to a point superior to the mesial root of $\mathrm{dP}^{3}$. The parastyle of $\mathrm{dP}^{3}$ is relatively short compared to the mesiodistally elongate metastyle. The paracone and metacone are fused at the base and for most of the height of the metacone. The apex of the metacone is distinct from the paracone, but it is a smaller, mesiodistally shorter cusp. The postmetacrista slopes to the deep carnassial notch formed with the metastyle. No buccal cingulum is observed along the buccal margin of the tooth, though it should be noted the specimens are heavily abraded. A thin, lingual cingulum traces the low and mesiodistally wide protocone. The primary cusp of the protocone rises only to the height of the parastyle.

The $\mathrm{dP}^{3}$ contacts $\mathrm{dP}^{4}$ lingual to the relatively small $\mathrm{dP}^{4}$ parastyle. The parastyle exhibits a small cusp that connects to the preparacrista. The paracone and metacone are fused for most of their height. The paracone is slightly taller than the lower, more buccolingually compressed metacone. The postmetacrista forms a distinct carnassial notch with the metastyle. The metastylar blade exhibits a slight undulation. The protocone of $\mathrm{dP}^{4}$ is mesiodistally narrower and projects more mesially than does the protocone of $\mathrm{dP}^{3}$. The distinct protocone cusp frames a shallow and clearly delineated trigon basin. The protocone on $\mathrm{dP}^{4}$ is low and does not rise to the level of the parastyle on $\mathrm{dP}^{4}$. The palate between the protocones of $\mathrm{dP}^{3}$ and $\mathrm{dP}^{4}$ and distal to the protocone of $\mathrm{dP}^{4}$ is deeply embayed, presumably to accommodate tall trigonids on $\mathrm{dP}_{4}$ and $\mathrm{M}_{1}$.

A second maxilla fragment of Leakitheirum, KNM-RU 15182 (Figure 3), also preserves $\mathrm{dP}^{3}$ and $\mathrm{dP}^{4}$. Both crowns are fragmented or worn, though 
TABLE 2. Measurements of the lower dentition. Asterisk indicates the measurements are based on the alveoli of the tooth. Length is mesiodistal length. Width is buccolingual length. $\sim$, indicates an approximate measurement based on fragmentary material. See methods for definitions of these measurements.

\begin{tabular}{lcccc}
\hline \multicolumn{1}{c}{ Taxon } & Specimen & Tooth & Length & Width \\
\hline Apterodon macrognathus & $\mathrm{DPC} 8217$ & $\mathrm{dP}_{3}$ & 11.7 & 3.8 \\
Anasinopa libyca & & $\mathrm{dP}_{4}$ & 15.7 & 4.9 \\
Masrasector nananubis & BMNH M82378 & $\mathrm{M}_{1}$ & 14.0 & 6.5 \\
& & $\mathrm{dP}_{3}$ & 9.9 & 2.2 \\
& & $\mathrm{dP}_{4}$ & 11.7 & 3.6 \\
& & $\mathrm{dP}_{3}$ & 5.2 & 1.6 \\
Masrasector nananubis 10358 & $\mathrm{dP}_{4}$ & 5.0 & 2.2 \\
& & $\mathrm{M}_{1}$ & 4.7 & 2.6 \\
& $\mathrm{DPC} 18276$ & $\mathrm{M}_{2}$ & 5.6 & 3.3 \\
& & $\mathrm{dP}_{2}$ & 3.9 & 1.5 \\
& & $\mathrm{dP}_{3}$ & 5.1 & 1.6 \\
& & $\mathrm{dP}_{4}$ & 4.7 & 1.8 \\
& & $\mathrm{P}_{2}$ & 9.2 & 2.4 \\
& $\mathrm{DPC} 4544$ & $\mathrm{dP}_{3}{ }^{*}$ & 12.0 & 2.6 \\
& & $\mathrm{dP}_{4}{ }^{*}$ & 10.4 & 3.0 \\
& & $\mathrm{M}_{1}$ & 10.6 & 4.7 \\
& & $\mathrm{M}_{2}$ & 12.6 & 5.2 \\
& & $\mathrm{M}_{3}$ & 213.82 & 4.3 \\
& & &
\end{tabular}

the morphology of the bases of each is consistent with the morphology observed on KNM-RU 2949, including the emergence of the infraorbital canal superior to the mesial root of $\mathrm{dP}^{3}$. KNM-RU 15182 also preserves the enamel bell of $\mathrm{P}^{4}$ in the crypt superior to the roots of $\mathrm{dP}^{4}$. The developing tooth bears the distinctive crenulated enamel often associated with Leakitherium (Savage, 1965; Lewis and Morlo, 2010). There is no developing tooth apparent in the crypt superior to $\mathrm{dP}^{3}$. This may be evidence that $\mathrm{P}^{4}$ developed and erupted before $\mathrm{P}^{3}$ in Leakitherium. It is also possible that the germ of $\mathrm{P}^{3}$ was more developed than $\mathrm{P}^{4}$ and fell out of the specimen when it was fractured along the $\mathrm{P}^{3}$ crypt.

\section{Remarks}

The holotype of Leakitherium (BMNH $M 19083$ ) is a pair of molars, $M^{1}$ and $M^{2}$, which both exhibit large protocones and expansive trigon basins (Savage, 1965). The lower dentition of Leakitherium has not been described. Some authors (Van Valen, 1967; Morales et al., 2007) have suggested Leakitherium hiwegi is the upper dentition of Isohyaenodon andrewsi. Holroyd (1999) made the case that the Metapterodon kai- seri (known from upper dentition) and Isohyaenodon andrewsi (known from lower dentition) are in fact synonymous, and Leakitherium is a distinct taxon. Neither Isohyaenodon andrewsi, nor Metapterodon kaiseri exhibit the distinct, crenulated enamel of Leakitherium. Further, Isohyaenodon does not possess distinct talonids nor the buccolingually broad trigonids expected to occlude with the $\mathrm{M}^{1}$ and $\mathrm{M}^{2}$ of Leakitherium. The specimens referred to Leakitherium in this study share the crenulated enamel and buccolingual breadth noted in the $\mathrm{M}^{1}$ and $\mathrm{M}^{2}$ of the holotype (Savage, 1965). The rugosity of the enamel is even more pronounced on the unerupted $\mathrm{P}^{4}$ (KNM-RU 15182, Figure 3), than on the more worn and abraded $\mathrm{dP}^{4}$. Based on these observations, we support the hypothesis of Holroyd (1999) that Leakitherium is a distinct taxon.

The Borths et al. (2016) analysis places Leakitherium within Hyainailourinae, a result congruent with earlier phylogenetic hypotheses (Lewis and Morlo, 2010). One feature uniting hyainailourines is the metacone morphology on $\mathrm{M}^{1}$ and $\mathrm{M}^{2}$, reduced into a buccolingually compressed cusp that is partially or almost entirely fused to the paracone 


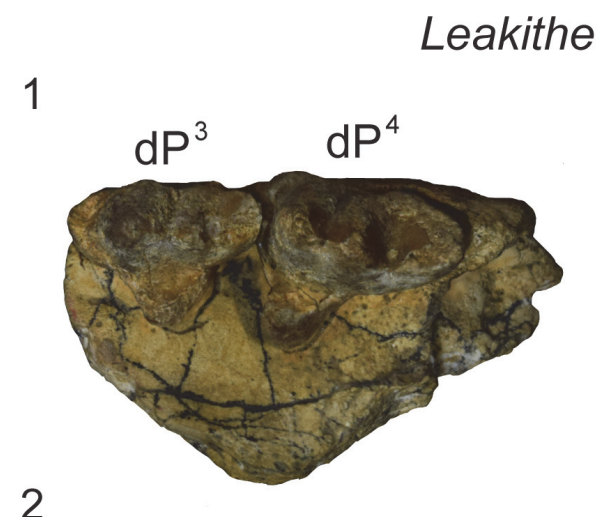

2
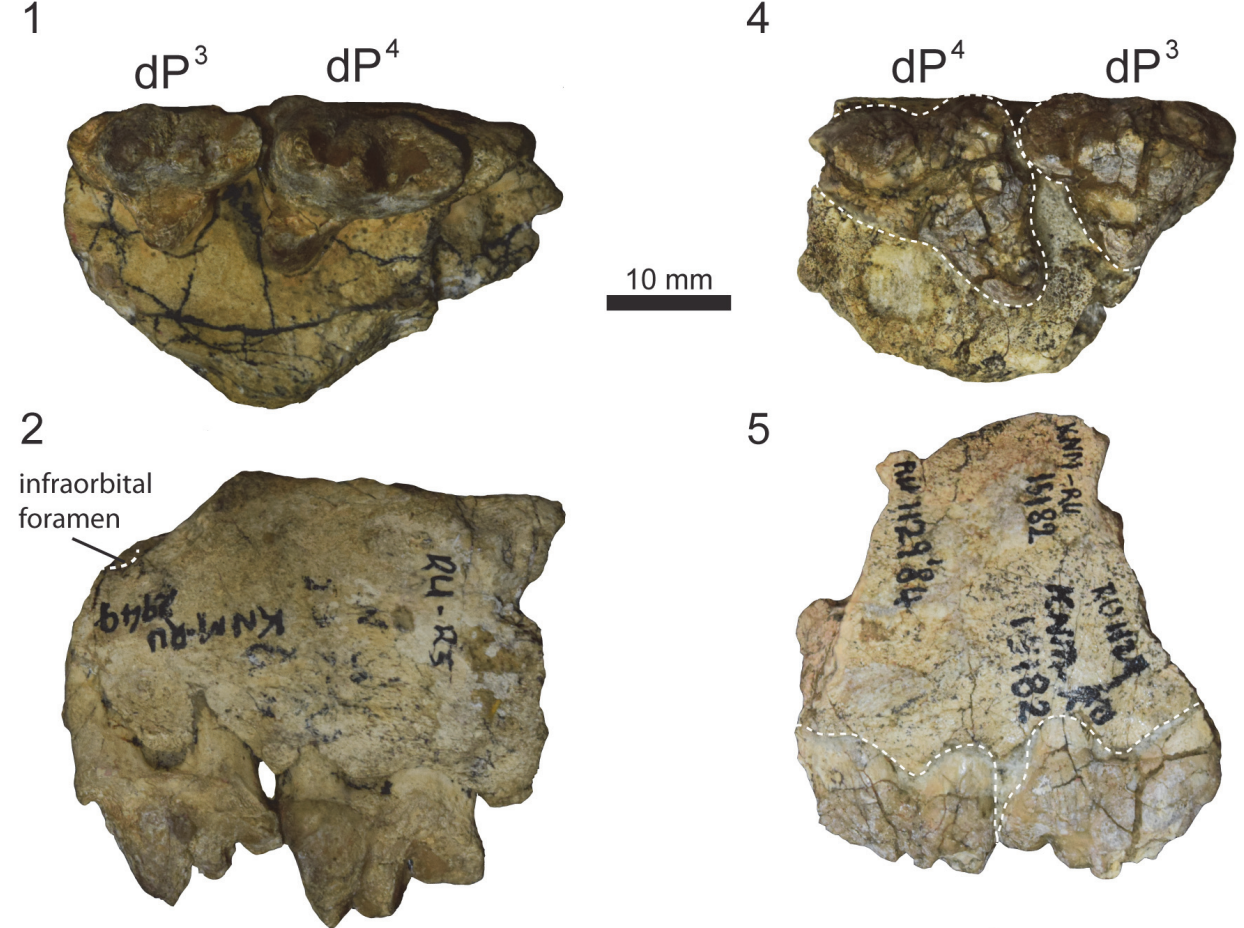

5

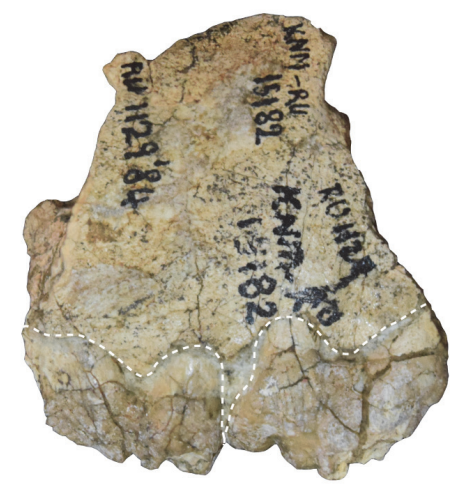

3

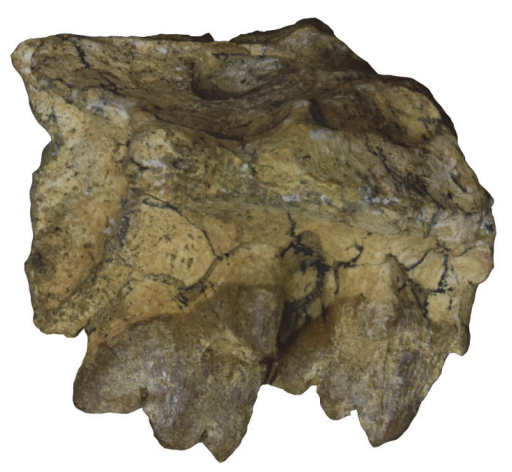

6
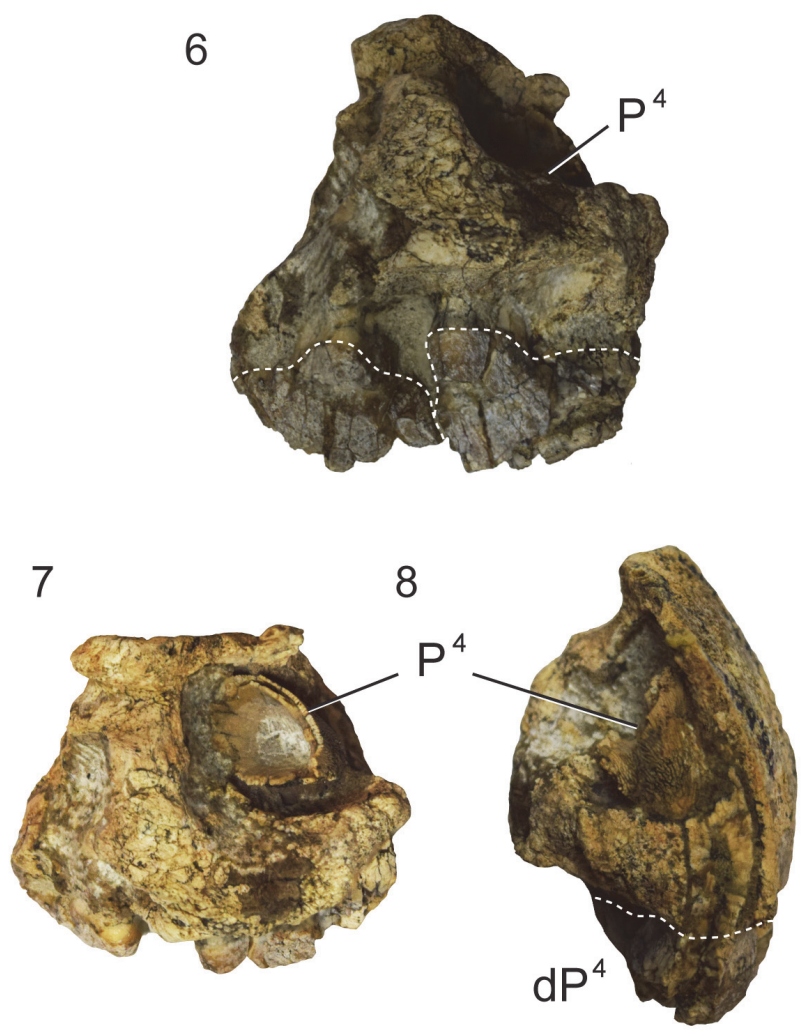

FIGURE 3. Leakitherium hiwegi maxilla fragments from Rusinga Island (early Miocene), Kenya. KNM-RU 2949 (CMF 4025 in Savage, 1965) is a left maxilla fragment $\mathrm{dP}^{3}$ and $\mathrm{dP}^{4}$ shown in 1) occlusal view; 2) buccal view; and 3) lingual view. KNM-RU 15182 is a right maxilla fragment with $\mathrm{dP}^{3}$ and $\mathrm{dP}^{4}$ and the germ of $\mathrm{P}^{4}$ shown in 4) occlusal view; 5) buccal view; 6) lingual view; 7) dorsal view; 8) and distal view. The well-developed germ of $\mathrm{P}^{4}$ is best viewed in dorsal and distal view. Specimens are to scale and scale bar is $10 \mathrm{~mm}$. 
(Borths et al., 2016). Interestingly, the $\mathrm{dP}^{4}$ of Leakitherium (Figure 3 ) exhibits a distinct metacone that is lower than and partially fused to the paracone, anticipating the morphology of $\mathrm{M}^{1}$ in the holotype of Leakitherium. Indeed, the morphology the $\mathrm{dP}^{4}$ metacone in Leakitherium is similar to the $\mathrm{dP}^{4}$ metacone of Paroxyaena pavlovi, a smaller hyainailourine from the late Eocene of France (Lavrov, 2007). This reflects the observation that in many mammals, a deciduous tooth resembles the adult tooth in the immediately distal position (Zack, 2012).

Deciduous teeth also provide additional features useful in differentiating among hyainailourine taxa. For example, $\mathrm{dP}^{3} \mathrm{~s}$ are known for at least three hyainailourines: Leakitherium, Paroxyaena, and Pterodon dasyuroides. Among these, Leakitherium exhibits the most individuated metacone on $\mathrm{dP}^{3}$ with a distinct furrow on the buccal surface of the tooth defining the bases of the paracone and metacone. In Pterodon and Paroxyaena the metacone is a low cusp with a distally pointing apex, lacking any deep furrow separating it from the paracone.

Leakitherium offers additional data on deciduous dental replacement order in Hyainailouroidea. The KNM-RU 15182 (Figure 3) specimen suggests that in Leakitherium, $\mathrm{dP}^{3}$ was retained longer than $\mathrm{dP}^{4}$. This deciduous replacement order is consistent with the deciduous replacement order that Bastl and Nagel (2013) observed in Hyaenodon, a hyaenodont taxon that likely diverged from the clade that includes Hyainailouroidea during the late Cretaceous or early Paleocene (Borths et al., 2016).

Subfamily TERATODONTINAE Savage, 1965 Genus ANASINOPA Savage, 1965

Type species. Anasinopa leakeyi Savage, 1965. Other included species. Anasinopa libyca Morales, Brewer, and Pickford, 2010.

\section{Anasinopa leakeyi Savage, 1965 \\ Figures 4-5, Tables 1-2}

Referred specimens. KNM-RU 2385, left maxilla fragment with $\mathrm{dP}^{2}, \mathrm{dP}^{3}$, and $\mathrm{dP}^{4}$ (Rusinga Island, Kenya).

\section{Description}

The description of the maxillary dentition of Anasinopa leakeyi (KNM-RU 2385, Figure 4) is based on a cast deposited in the Rusinga collection at the National Museums of Kenya. A note on the specimen label speculates the original may
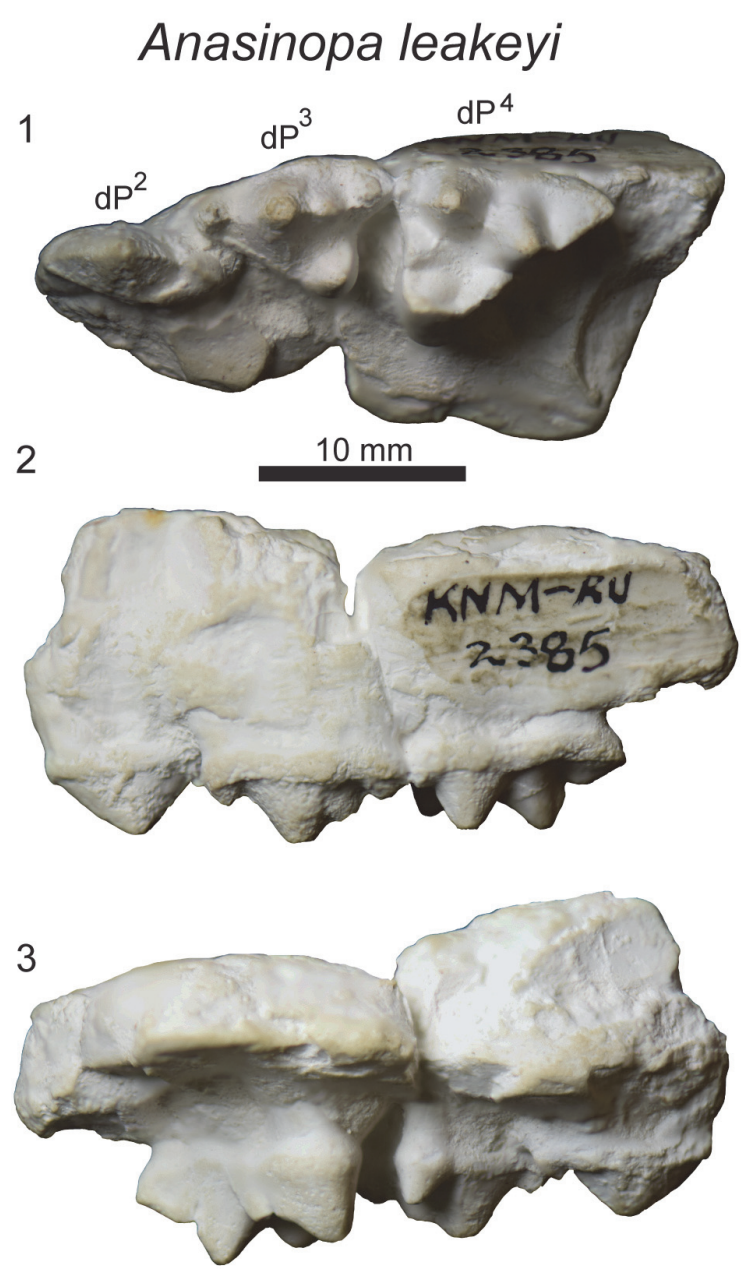

FIGURE 4. Anasinopa leakeyi left maxilla cast with $\mathrm{dP}^{2}$, $\mathrm{dP}^{3}$ and $\mathrm{dP}^{4}$ (KNM-RU 2385) from Rusinga Island (early Miocene), Kenya in 1) occlusal view; 2) buccal view; and 3) lingual view. Scale bar is $10 \mathrm{~mm}$.

have been lent to Savage, but the exact location of the original specimen is unknown. The specimen preserves $\mathrm{dP}^{2}, \mathrm{dP}^{3}$, and $\mathrm{dP}^{4}$. There is an indentation on the buccal surface of the cast superior to the mesial root of $\mathrm{dP}^{3}$ that suggests the infraorbital foramen is preserved in the original, though it is not as clear on the cast. The morphology of the dental crowns appears to be accurately captured, with no evidence of bubbles in the plaster, making the detailed description of the deciduous upper dentition possible based on the cast of KNM-RU 2385.

The $\mathrm{dP}^{2}$ is a buccolingually compressed tooth with a long, low paracone with a height less than half the mesiodistal length of the tooth. A small metastyle is present at the distal point of the tooth, forming a distinct, but small notch between the paracone and metastyle. A clear buccal cingulum traces the buccal surface of the tooth from the 


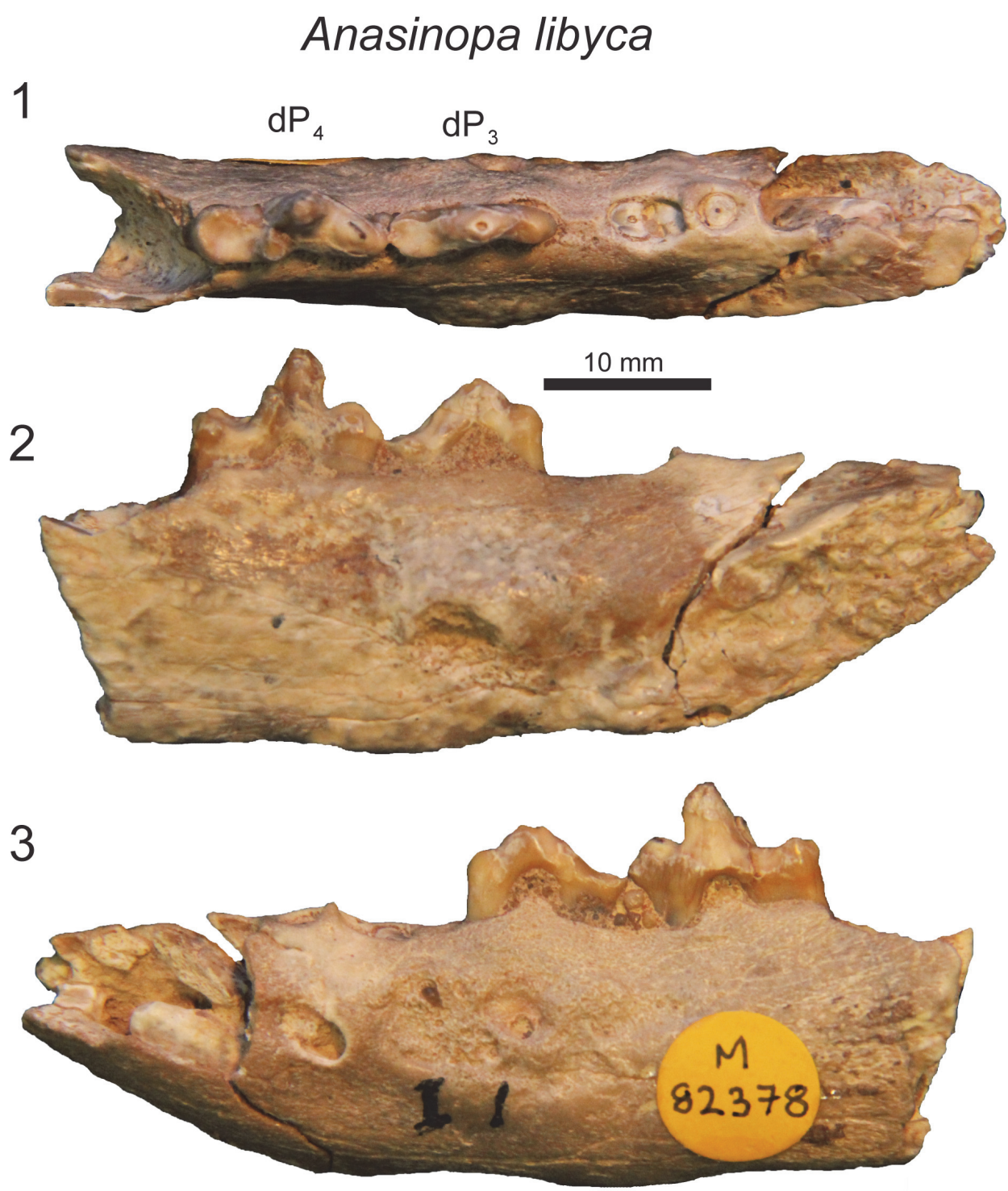

FIGURE 5. Anasinopa libyca left dentary with $\mathrm{dP}_{3}$ and $\mathrm{dP}_{4}$ from Gebel Zelten (middle Miocene), Libya (BMNH M82378) in 1) occlusal view; 2) lingual view; 3) buccal view. Scale bar is $10 \mathrm{~mm}$.

parastyle to the metastyle. The mesiodistal length of the $\mathrm{dP}^{2}$ metastyle is less than $25 \%$ of the total length of the tooth. The buccal surface of the metastyle is braced by the parastyle of $\mathrm{dP}^{3}$ such that the buccal face of the $\mathrm{dP}^{2}$ metastyle is blocked by the parastyle of $\mathrm{dP}^{3}$ in buccal view.

The $\mathrm{dP}^{3}$ bears a mesiodistally elongate parastyle that is the same length as the metastyle. The parastyle is a single, distinct cusp that forms a notch where it intersects the preparacrista. The preparacrista rises to the apex of the paracone at a 45 degree angle. The paracone is the tallest cusp on $\mathrm{dP}^{3}$. The postparacrista is buccolingually compressed, as is the metacone which is a long, low cusp that forms a notch with the postparacrista. The metacone is less than half the height of the paracone. The metastyle forms a distinct carnassial notch with the metacone and rises to the same height as the parastyle and is only half the height of the metacone. On the distobuccal surface of $\mathrm{dP}^{3}$ is a shallow buccal basin framed by the metacone, metastyle, and buccal cingulum. The protocone projects distolingually from the base of the paracone. The protocone is the same height as the carnassial notch of $\mathrm{dP}^{3}$. In occlusal view the proto- 
cone is triangular, with the mesial and distal margins of the cusp intersecting at a wide angle with no indication of a metaconule or paraconule. A thin lingual cingulum connects the parastyle to the protocone. The metastyle of $\mathrm{dP}^{3}$ contacts the mesialmost point of the parastyle of $\mathrm{dP}^{4}$.

The mesiodistal length of $\mathrm{dP}^{4}$ is only slightly longer than $\mathrm{dP}^{3}$. The parastyle of $\mathrm{dP}^{4}$ is smaller and more cingulum-like than the distinct, cusp-like parastyle on $\mathrm{dP}^{3}$. On $\mathrm{dP}^{4}$ a distinct buccal cingulum connects the parastyle to the metastyle. Distal to the parastyle, the paracone and metacone are divergent cusps from their bases to their apices. The paracone is only slightly buccolingually compressed, and its base is circular in cross section. The metacone is more buccolingually compressed than the paracone and is more lingually positioned than the paracone. The postmetacrista is sectorial, forming a deep carnassial notch with the metastyle. The mesiodistal length of the metastyle is subequal to the mesiodistal length of the metacone base. The metastyle is blade-like with a distinct convex crista that gently inflects distally. The metastyle does not connect to the protocone. Instead, a large metaconule that is the same height as the carnassial notch arises near the distal base of the metacone. A small, but distinct notch is formed between the metaconule and protocone. The protocone is a tall cusp that is subequal in height to the paracone. The apex of the protocone points in a mesiobuccal direction. Compared with the protocone of $\mathrm{dP}^{3}$, the protocone of $\mathrm{dP}^{4}$ is mesially shifted and buccolingually aligned with the paracone in occlusal view. The mesial margin of the protocone forms a small notch with the paraconule. The paraconule is as large and welldefined as the metaconule. A thin lingual cingulum connects the paraconule to the parastyle. The large protocone, paraconule, metaconule, and divergent paracone and metacone frame a wide and deep trigon basin. The mesial roots of $\mathrm{M}^{1}$ are preserved on the specimen, indicating the protocone of $\mathrm{M}^{1}$ projected more lingually than the protocone of $\mathrm{dP}^{4}$. The mesiobuccal root of $\mathrm{M}^{1}$ also indicates the metastyle of $\mathrm{dP}^{4}$ was aligned with the parastyle of $\mathrm{M}^{1}$.

Morales et al. (2010) described portions of the lower deciduous dentition of Anasinopa libyca from the early middle Miocene of Libya. Here we provide additional description of this specimen (Figure 5), discovered by R. J. G. Savage, which preserves the morphology $\mathrm{dP}_{3}$ and $\mathrm{dP}_{4}$. There is a short diastema between the distal alveolus of $\mathrm{dP}_{2}$ and $\mathrm{dP}_{3}$.
$\mathrm{dP}_{3}$ is buccolingually compressed with a mesiodistally extensive paraconid. $\mathrm{dP}_{3}$ is heavily abraded, but there was a distinct talonid basin. Like $\mathrm{dP}_{3}$, the trigonid of $\mathrm{dP}_{4}$ is buccolingually compressed. The bases of the paraconid and protoconid are subequal in length. The postprotocristid slopes to a small metaconid at the distal-most margin of the protoconid base. The small metaconid is less than half the height of the protoconid. The talonid basin of $\mathrm{dP}_{4}$ is shallow, and enclosed lingually by the entocristid, which connects with the base of the metaconid. The talonid basin of $\mathrm{dP}_{4}$ is demarcated by a low, but distinct hypoconid and hypoconulid and a slight entoconid that grades into the entocristid.

\section{Remarks}

Recent phylogenetic analyses resolve Anasinopa within Teratodontinae, an entirely Afro-Arabian clade (Solé et al., 2014; Rana et al., 2015; Borths and Seiffert, 2017). In the topologies described by Borths et al. (2016) and Borths and Seiffert (2017) Teratodontinae is the sister clade of Hyainailouridae (Apterodontinae + Hyainailourinae). Teratodontinae is generally characterized by dental features shared with mesocarnivores including divergent paracones and metacones, basined talonids, and the presence of metaconids. However, within Teratodontinae, some taxa, like Anasinopa, combine this mesocarnivorous morphology with hallmarks of hypercarnivores like exaggerated metastyles and tall, buccolingually compressed metacones. Borths et al. (2016) demonstrated that teratodontines specifically converged with the hypercarnivorous dental morphology of Hyaenodontinae. Despite convergent features associated with hypercarnivory, synapomorphies between the deciduous dentition of Anasinopa and the deciduous dentition of other teratodontines consistently place this hypercarnivorous, wolf-sized hyaenodont within Teratodontinae.

In several recent phylogenetic analyses (Rana et al., 2015; Borths and Seiffert, 2017) Dissopsalis and Anasinopa are closely related taxa within Teratodontinae and both taxa are found in early to middle Miocene sites. The two genera differ in size, with Anasinopa slightly smaller than Dissopsalis. The adult dentitions of Dissopsalis and Anasinopa both mix mesocarnivorous and hypercarnivorous dental features, with $M_{1}$ and $M_{2}$ retaining the well-developed talonid basins of mesocarnivores, but the talonid of $\mathrm{M}_{3}$ reduced to a single cusp and the carnassial blade of $\mathrm{M}_{3}$ 
expanded as would be expected in hypercarnivores. When Dissopsalis and Anasinopa are directly compared, Dissopsalis has more exaggerated hypercarnivorous dental features, with more reduced paracones on the upper molars and more elongate carnassial blades.

The maxillary specimen, KNM-RU 2385 (Figure 4), is consistent in size with Anasinopa and the expanded trigon basins, mesiodistally shorter metastyles, and widely divergent paracone and metacone on $\mathrm{dP}^{4}$ are also consistent with the adult dental morphology of Anasinopa. The deciduous dentition of Anasinopa and Dissopsalis are similar, although several characters can be used to distinguish these taxa. Anasinopa has a $\mathrm{dP}^{3}$ metacone that is mesiodistally shorter than the $\mathrm{dP}^{3}$ metacone of Dissopsalis. Further, the metastyle on $\mathrm{dP}^{3}$ in Anasinopa is also mesiodistally shorter than the $\mathrm{dP}^{3}$ metastyle of Dissopsalis. The $\mathrm{dP}^{3}$ buccal cingulum of Anasinopa is wider and more distinct than is the buccal cingulum of Dissopsalis. Like the metastyle on $\mathrm{dP}^{3}$, the metastyle of $\mathrm{dP}^{4}$ in Anasinopa is relatively shorter than the metastyle on $\mathrm{dP}^{4}$ in Dissopsalis. The protocone on $\mathrm{dP}^{4}$ of Anasinopa bears a more distinct paraconule and metaconule than the protocone of $\mathrm{dP}^{4}$ in Dissopsalis, and the margins of the protocone in Anasinopa meet at a wider angle, giving the protocone a broader, triangular shape in occlusal view than the mesiodistally narrowed $\mathrm{dP}^{4}$ protocone of Dissopsalis.

Masrasector is also nested within Teratodontinae and is closely related to Anasinopa. Anasinopa is larger than Masrasector, but the two taxa share divergent metacones and paracones on $\mathrm{dP}^{4}$. Also on $\mathrm{dP}^{4}$ in both Masrasector and Anasinopa, the metacone is lingually placed relative to the paracone rather than mesiodistally aligned with the paracone as it is in Dissopsalis, Leakitherium, and Apterodon. The divergent $\mathrm{dP}^{4}$ paracones, metacones, and protocones of both Masrasector and Anasinopa surround broad trigon basins.

In teratodontines the $\mathrm{M}^{1}$ and $\mathrm{M}^{2}$ paracones are subequal to or lower than the metacones, leaving the metacone as the lead piercing cusp on the molars. In Anasinopa, dP4 anticipates the morphology of the adult molars by exhibiting a slightly taller metacone than paracone, morphology that is shared with the $\mathrm{dP}^{4}$ of Masrasector. The $\mathrm{dP}^{4}$ of Anasinopa shares with the $\mathrm{dP}^{4}$ of the teratodontines Brychotherium, Masrasector, and Metasinopa, a broad shelf between the metastyle, metacone, and buccal cingulum. Dissopsalis lacks this broad distal buccal shelf.
The dentary of Anasinopa libyca preserves $\mathrm{dP}_{3}$ and $\mathrm{dP}_{4}$ (Figure 5). Morales et al. (2010) noted A. libyca is 10 to $25 \%$ smaller than $A$. leakeyi, the species to which we refer KNM-FT 3357. $\mathrm{dP}_{4}$ in $A$. libyca shares with the $\mathrm{dP}_{4}$ of Masrasector and Metasinopa a distinct metaconid that is only slightly lower than the paraconid. These three teratodontines also share a mesiodistally elongate talonid basin with distinct hypoconids and hypoconulids. A. libyca and Metasinopa differ from Masrasector in lacking distinct entoconids on the lingual margin of the talonid basin. Instead, A. libyca and Metasinopa both exhibit smooth entocristids that close the lingual margin of the talonid.

Genus DISSOPSALIS Pilgrim, 1910

Type species. Dissopsalis carnifex Savage, 1965. Other included species. Dissopsalis pyroclasticus Barry, 1988.

\section{Dissopsalis pyroclasticus Barry, 1988 Figure 6, Table 1}

Referred specimens. KNM-FT 3357, left maxilla fragment with $\mathrm{dP}^{3}$ and $\mathrm{dP}^{4}$ (Fort Ternan, Kenya).

\section{Description}

The maxillary specimen, KNM-FT 3357 (Figure 6), is referred to Dissopsalis based on comparisons with other material referred to Dissopsalis from Fort Ternan, including KNM-FT 3562, a close size match to KNM-FT 3357. It is possible this represents the upper deciduous dentition of Anasinopa, but based on morphological comparisons detailed below we identify the Fort Ternan specimen as a maxillary fragment of Dissopsalis, and refer the slightly smaller KNM-RU 2385 (Figure 4) to Anasinopa.

Only fragmentary portions of the lateral margin of the maxilla are preserved on KNM-FT 3357, including the inferior margin of the infraorbital foramen superior to the mesial root of $\mathrm{dP}^{3}$. A single alveolus of $\mathrm{P}^{1}$ is preserved at the rostral-most portion of the specimen. Based on the fragmentary preservation of this alveolus, it is difficult to determine whether this tooth had a single root in the single alveolus, or if this is the distal of two roots. Both alveoli of $\mathrm{dP}^{2}$ are preserved. The distal alveolus of that tooth position exhibits a larger circumference than does the mesial root, crowding the mesial margin of $\mathrm{dP}^{3}$. The morphology of this distal alveolus indicates $\mathrm{dP}^{2}$ and $\mathrm{dP}^{3}$ would have been closely packed with the metastyle of $\mathrm{dP}^{2}$ braced buccally by the parastyle of $\mathrm{dP}^{3}$. 


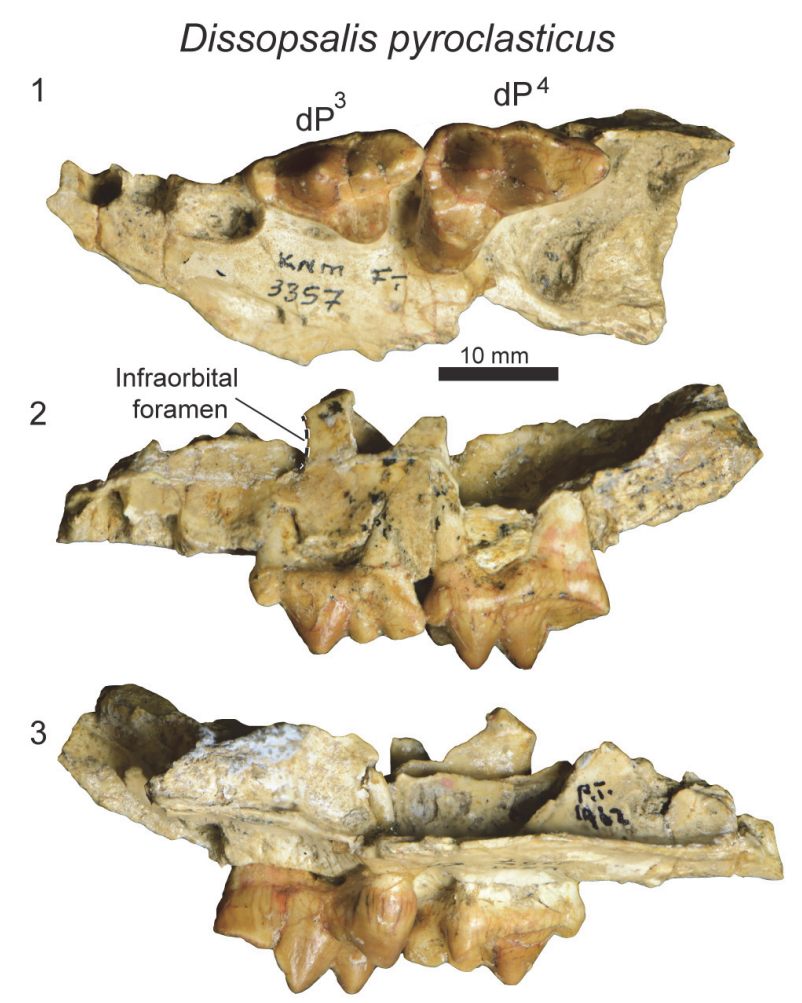

FIGURE 6. Dissopsalis pyroclasticus left maxilla with $\mathrm{dP}^{3}$ and $\mathrm{dP}^{4}$ (KNM-FT 3357) from Fort Ternan (early Miocene), Kenya in 1) occlusal view; 2) buccal view; and 3) lingual view. Scale bar is $10 \mathrm{~mm}$.

The entire crown of $\mathrm{dP}^{3}$ is preserved. The mesiodistal length of the parastyle and metastyle are subequal. The parastyle and metastyle are mesiodistally aligned and are intersected at a perpendicular angle by the protocone. The parastyle, metastyle and protocone are distinct cusps, but each is relatively low compared to the paracone, which is the tallest cusp on the tooth. The mesiodistal length of the paracone is subequal to the height of the paracone, making the cusp appear long and low in buccal view. The preparacrista is twice the length of the postparacrista, which intersects the metacone. The metacone is distinct, only half the height of the paracone, and exhibits greater convexity along the buccal surface than the lingual surface. The metacone forms a shallow carnassial notch with the short, low metastyle. The parastyle and metastyle are connected to the large protocone, defining the mesial and distal margins of the wide trigon basin. The protocone on $\mathrm{dP}^{3}$ is distally oriented, defining a relatively narrow space between the lingual aspects of $\mathrm{dP}^{3}$ and $\mathrm{dP}^{4}$.

In Dissopsalis (KNM-FT 3357, Figure 6) $\mathrm{dP}^{4}$ is mesiodistally only slightly longer than $\mathrm{dP}^{3}$, though the relative proportions of the cusps are very different with the distinct parastyle mesiodistally shorter than the metastyle and the protocone shifted mesially so that it is lingual to the paracone. The small, cusp-like parastyle connects the distinct buccal cingulum of $\mathrm{dP}^{4}$ to the paraconule. The paracone and metacone are fused for about half of their height, then the apices diverge, with both oriented perpendicular to the palate. The paracone and metacone are subequal in mesiodistal length, and the metacone is slightly taller than the paracone. Both the metacone and paracone are buccolingually compressed. The distal margin of the metacone is the most compressed and sectorial portion of these cusps. The metacone forms a distinct, though shallow, carnassial notch where it intersects the metastyle. The metastyle is lower than the metacone and comparable in height to the parastyle. The protocone is a mesiodistally broad cusp that is subequal in height to the parastyle. The protocone frames the lingual margin of a deep trigon basin that is buccally defined by the paracone, mesially defined by a distinct paraconule, and distally defined by a distinct metaconule.

\section{Remarks}

Dissopsalis is one of the last teratodontines documented in the fossil record (Solé et al., 2015) and is also one of the most hypercarnivorous, as reflected by the elongate metastyle and buccolingually compressed metacone on $\mathrm{dP}^{4}$ in KNM-FT 3357 (Figure 6). The $\mathrm{dP}^{3}$ of Dissopsalis shares with Masrasector, Metasinopa, Anasinopa, and Pakakali a low metacone and a mesiodistally elongate metastyle. The $\mathrm{dP}^{3}$ of Dissopsalis and Anasinopa are distinct from Masrasector and from the other hyainailouroid $\mathrm{dP}^{3}$ specimens considered in this study by having a mesiodistally elongate paracone with a low buccal profile and a mesiodistally elongate metacone. The carnassial notch of $\mathrm{dP}^{3}$ in Dissopsalis also differs from all other hyainailouroids by being relatively shallow rather than defined by a deep notch that almost divides the metastyle and metacone down to the buccal cingulum.

In teratodontines the $\mathrm{M}^{1}$ and $\mathrm{M}^{2}$ paracones are subequal to or lower than the metacones, leaving the metacone as the lead piercing cusp on the molars. In Dissopsalis the $\mathrm{dP}^{4}$ anticipates the morphology of the adult molars in exhibiting a slightly taller metacone than paracone, morphology that is shared with the $\mathrm{dP}^{4}$ of Masrasector and Anasinopa. Unlike Anasinopa, the bases of the paracone 
and metacone on $\mathrm{dP}^{4}$ in Dissopsalis are partially fused, also anticipating the more fused paracone and metacone found on the molars of Dissopsalis. The $\mathrm{dP}^{4}$ of Dissopsalis differs from the $\mathrm{dP}^{4}$ of the teratodontines Brychotherium, Masrasector, and Metasinopa, in having a constricted space between the metastyle, metacone, and buccal cingulum. Overall, the more exaggerated hypercarnivorous characters evident on the deciduous dentition of Dissopsalis reveal dietary adaptations that are important for interpreting the biology of one of the latest surviving hyaenodonts in Afro-Arabia.

\section{Genus MASRASECTOR Simons and Gingerich,} 1974

Type species. Masrasector aegypticum Simons and Gingerich, 1974.

Other included species. Masrasector ligabuei Crochet, Thomas, Roger, and Al-Sulaimani, 1990; Masrasector nananubis Borths and Seiffert, 2017.

Masrasector nananubis Borths and Seiffert, 2017 Figures 7-9, Tables 1-2

Referred specimens. DPC 20882, right maxilla fragment with $\mathrm{dP}^{3}$ and $\mathrm{dP}^{4}$ (Fayum Depression, Jebel Qatrani Formation, Quarry L-41); DPC 13837, right maxilla fragment with $\mathrm{dP}^{3}, \mathrm{dP}^{4}, \mathrm{M}^{1}$ (Fayum Depression, Jebel Qatrani Formation, Quarry L-41); DPC 18276, right dentary with $\mathrm{dP}_{2}$, $\mathrm{dP}_{3}, \mathrm{dP}_{4}$ (Fayum Depression, Jebel Qatrani Formation, Quarry L-41). Note: These specimens were all found in isolation in Quarry L-41 and are not likely associated.

\section{Description}

The upper deciduous dentition of Masrasector nananubis is best represented by the two maxillary fragments we identify here: DPC 20882 and DPC 13837 (Figure 7). Both are right maxillary fragments preserving portions of $\mathrm{dP}^{3}$ and $\mathrm{dP}^{4}$. DPC 13837 further preserves $M^{1}$, illustrated here to highlight some of the differences between $\mathrm{dP}^{4}$ and $\mathrm{M}^{1}$.

The infraorbital foramen is preserved in both specimens superior to the mesial root of $\mathrm{dP}^{3}$. The parastyle of $\mathrm{dP}^{3}$ is elongate and buccolingually compressed into a narrow crista that connects with the preparacrista of the paracone. The $\mathrm{dP}^{3}$ is best preserved on DPC 20882 where the parastyle is mesiodistally subequal in length to the metastyle and is subequal in height to the apex of the metastyle. A thin buccal cingulum connects the parastyle to the metastyle. The paracone is the tallest cusp on $\mathrm{dP}^{3}$. The apex of the paracone forms an equilateral triangle in buccal view. The metacone is half the height of the paracone and it is closely appressed to the paracone, though it is a distinct cusp with a shallow furrow defining the margins of the metacone where it fuses with the paracone. In occlusal view, the metacone is positioned slightly lingual to the apex of the paracone. The metacone forms a deep carnassial notch at the juncture with the sectorial metastyle. A thin shelf is formed between the metastyle, the metacone, and the buccal cingulum. The protocone is mesiodistally narrow and isolated from the parastyle and metastyle.

The crown of $\mathrm{dP}^{4}$ is best preserved on DPC 20882 (Figure 7). The parastyle is a distinct cusp that is mesiodistally shorter than the metastyle. As on $\mathrm{dP}^{3}$ and $\mathrm{M}^{1}$ (DPC 13837) the parastyle and metastyle of $\mathrm{dP}^{4}$ are connected by a distinct buccal cingulum. The paracone and metacone are fused at their bases and diverge near the midpoint of their height. The paracone and metacone are subequal in height, are slightly buccolingually compressed and have similar basal diameters. The paracone is proximate to the buccal cingulum with the metacone positioned more lingually. The postmetacrista meets the metastyle at a deep carnassial notch. A wide basin is formed between the sectorial metastyle, the buccal cingulum, and the bases of the paracone and metacone. The buccal cingulum traces a shallow ectoflexus. The protocone is mesially oriented and lingually aligned with the mesial margin of the parastyle. A thin mesial cingulum connects the parastyle to the protocone, but the protocone is not connected to the metastyle. The protocone is a mesiodistally broad cusp that projects beyond the divergence of the paracone and metacone.

Maxillary specimens of Masrasector (Figure 7) were $\mu$-CT scanned, revealing that the developing permanent dentition has not reached the bell stage of differentiation in DPC 20882, a specimen that only preserves $\mathrm{dP}^{3}$ and $\mathrm{dP}^{4}$. DPC 13837 (Figure 7 ) preserves a fully erupted $M 1$ with open roots, and developing portions of $\mathrm{P}^{3}$ and $\mathrm{P}^{4}$ that both advanced into the bell phase of tooth differentiation. The paracone of $\mathrm{P}^{3}$ has coalesced in the crypt, framed by the roots of $\mathrm{dP}^{3}$. The paracone of $\mathrm{P}^{4}$ had only just started to coalesce in the crypt, evidence that in Masrasector, $\mathrm{P}^{3}$ likely erupted before $\mathrm{P}^{4}$.

The lower deciduous dentition of Masrasector nananubis was described by Borths and Seiffert (2017), though that previous study did not detail 


\section{Masrasector nananubis}
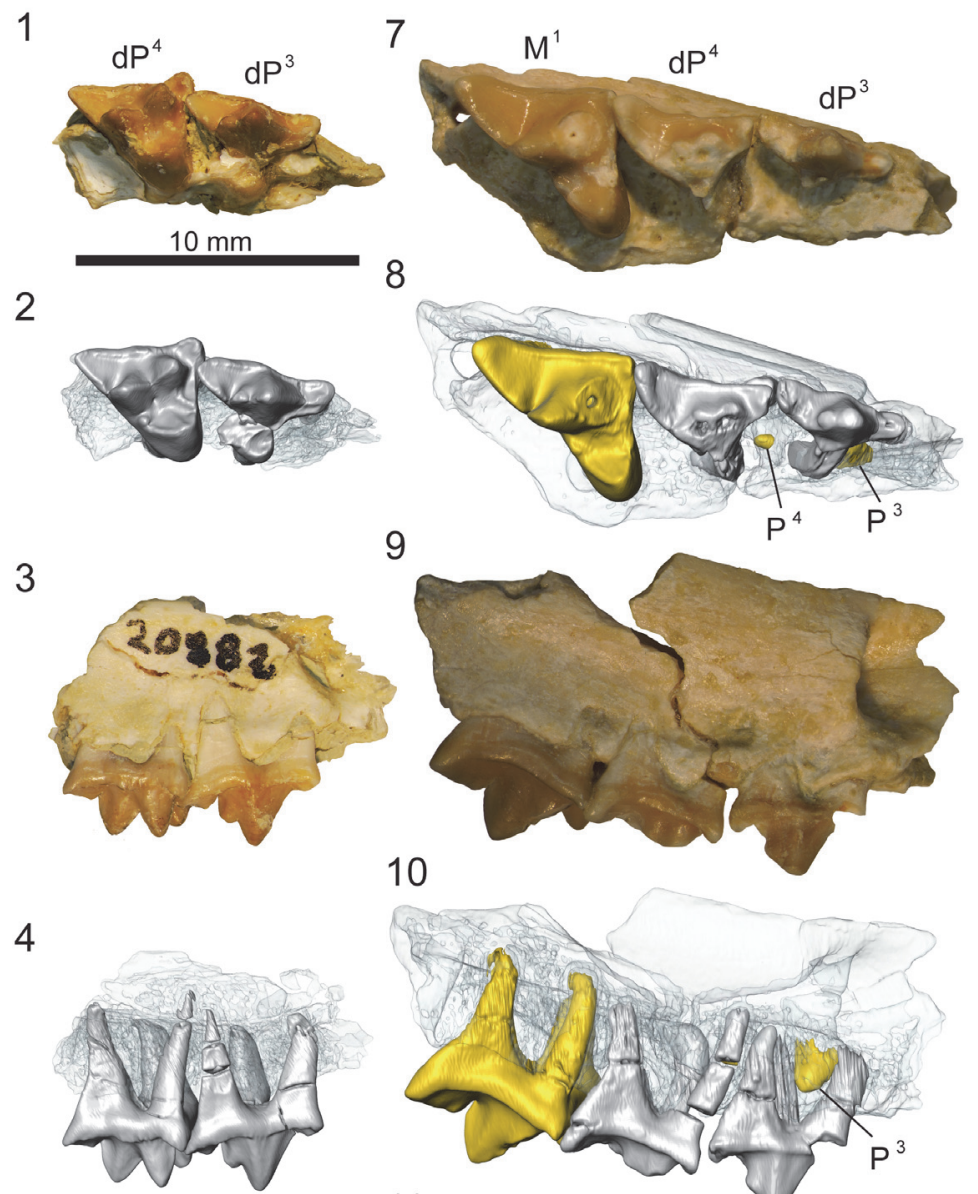

10
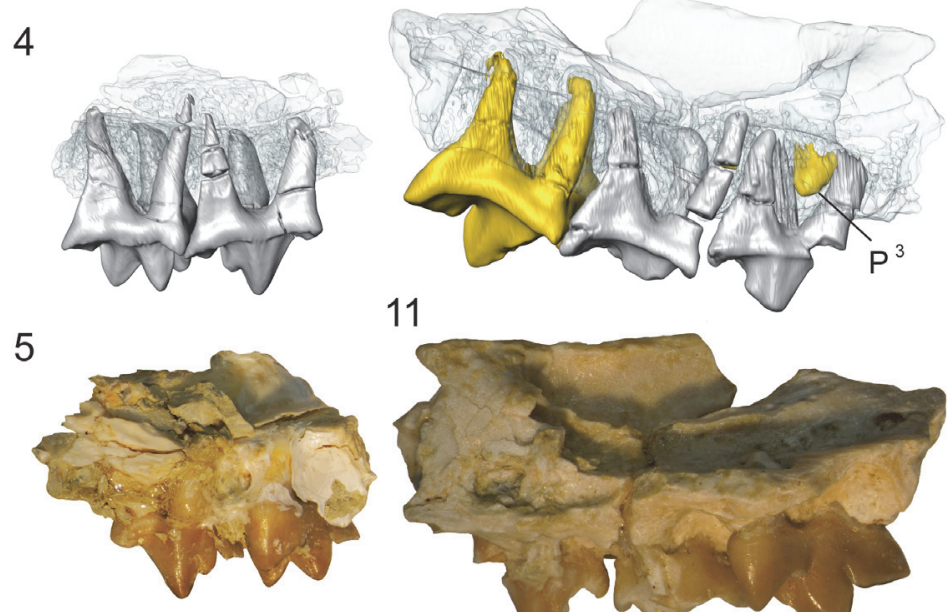

11
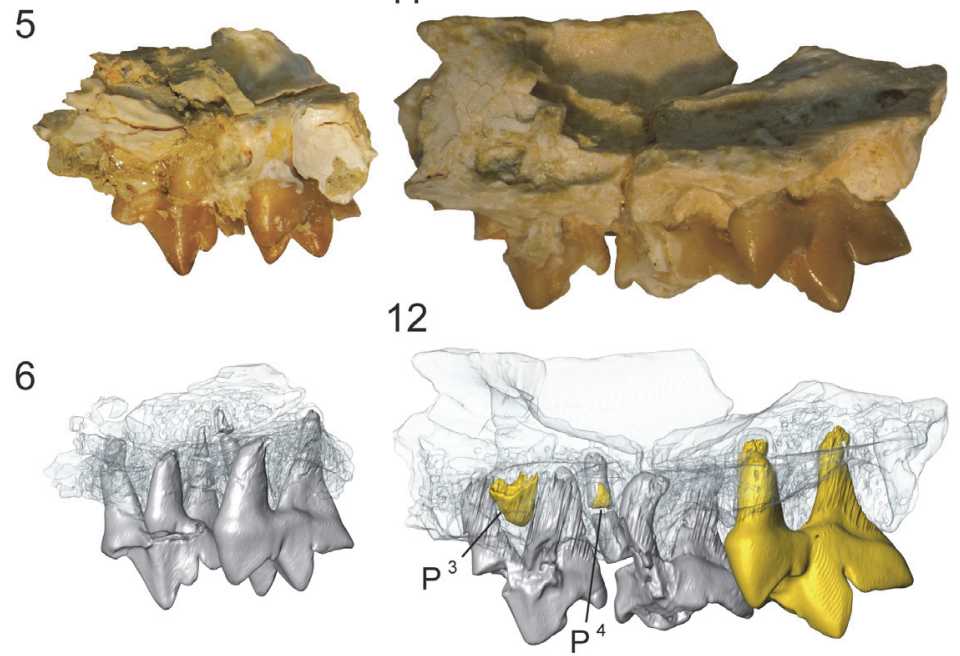

FIGURE 7. Masrasector nananubis left maxillae from Locality 41 (latest Eocene), Fayum Depression, Egypt. Original specimens figured with digital models based on $\mu$-CT scans reconstructed in Avizo. Maxilla rendered transparent to reveal developing dentition. Grey, deciduous dentition. Yellow, permanent dentition. DPC 20882 is a left maxilla fragment that preserves $\mathrm{dP}^{3}$ and $\mathrm{dP}^{4}$ and no indication of developing permanent dentition. 1) specimen occlusal view; 2) model occlusal view; 3) specimen buccal view; 4) model buccal view; 5) specimen lingual view; 6) model lingual view. DPC 13837 is a left maxilla fragment that preserves erupted $\mathrm{dP}^{3}, \mathrm{dP}^{4}$, and $\mathrm{M}^{1}$ and $\mathrm{P}^{3}$ and $\mathrm{P}^{4}$ developing in crypts. 7) specimen occlusal view; 8) model occlusal view; 9) specimen buccal view; 10) model buccal view; 11) specimen lingual view; 12) model lingual view. Scale bar is $10 \mathrm{~mm}$. 


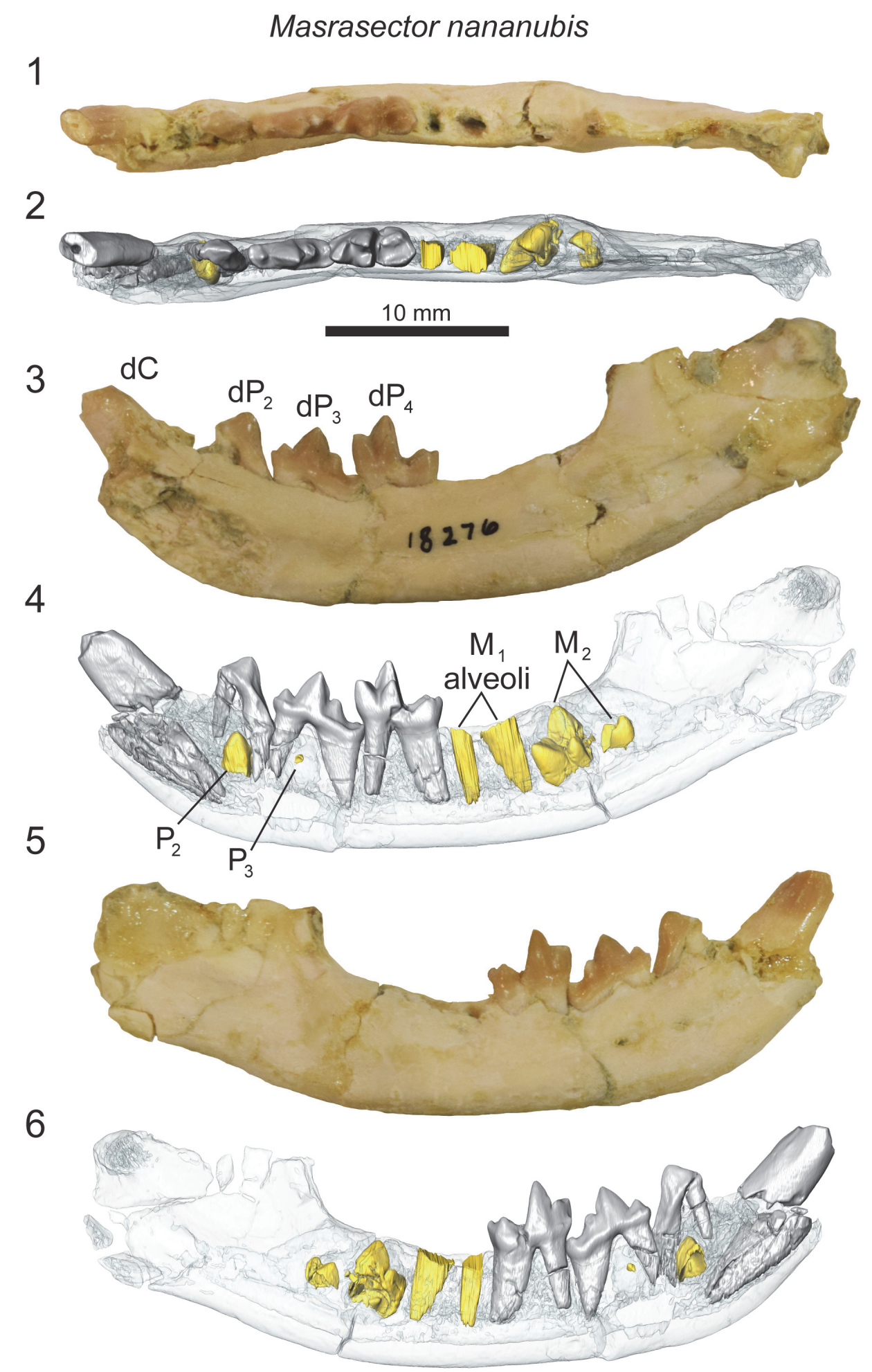

FIGURE 8. Masrasector nananubis right dentary with erupted $\mathrm{dC}, \mathrm{dP}_{2}, \mathrm{dP}_{3}$, and $\mathrm{dP}_{4}, \mathrm{M}_{1}$ alveoli and $\mathrm{P}_{2}, \mathrm{P}_{3}$, and $\mathrm{M}_{2}$ in crypts (DPC 18276) from Locality 41 (latest Eocene), Fayum Depression, Egypt. Original specimen figured with digital model based on $\mu$-CT scans reconstructed in Avizo. Dentary rendered transparent to reveal developing dentition. Grey, deciduous dentition. Yellow, permanent dentition. 1) specimen occlusal view; 2) model occlusal view; 3) specimen lingual view; 4) model lingual view; 5) specimen buccal view; 6) model buccal view. Scale bar is $10 \mathrm{~mm}$. 


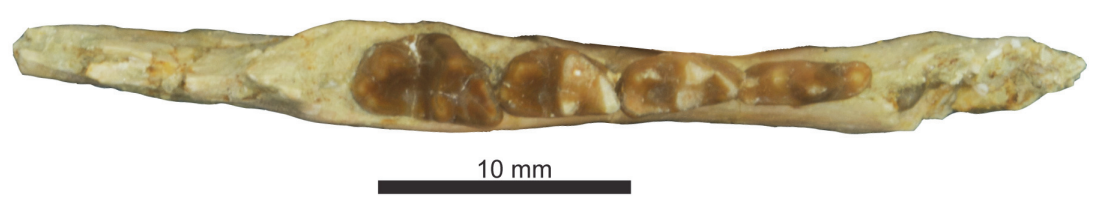

2

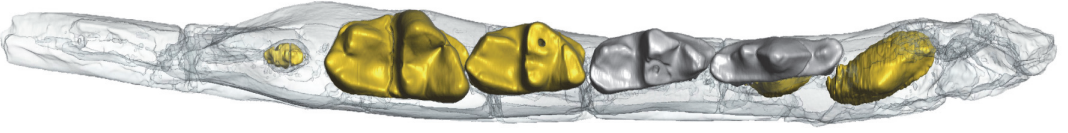

3

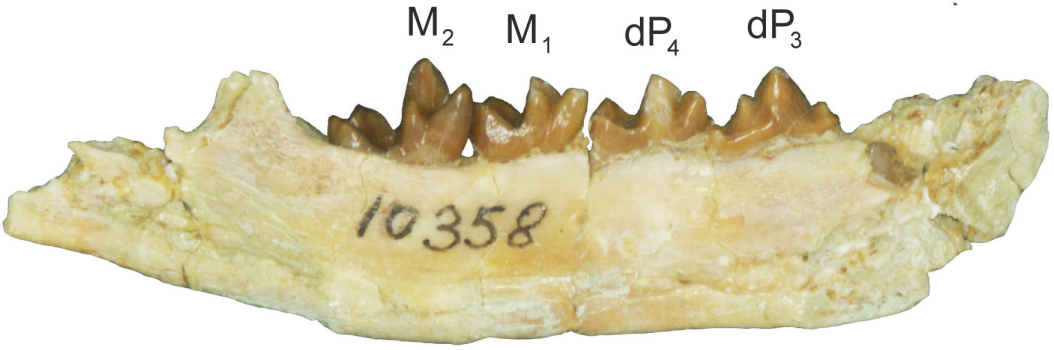

4
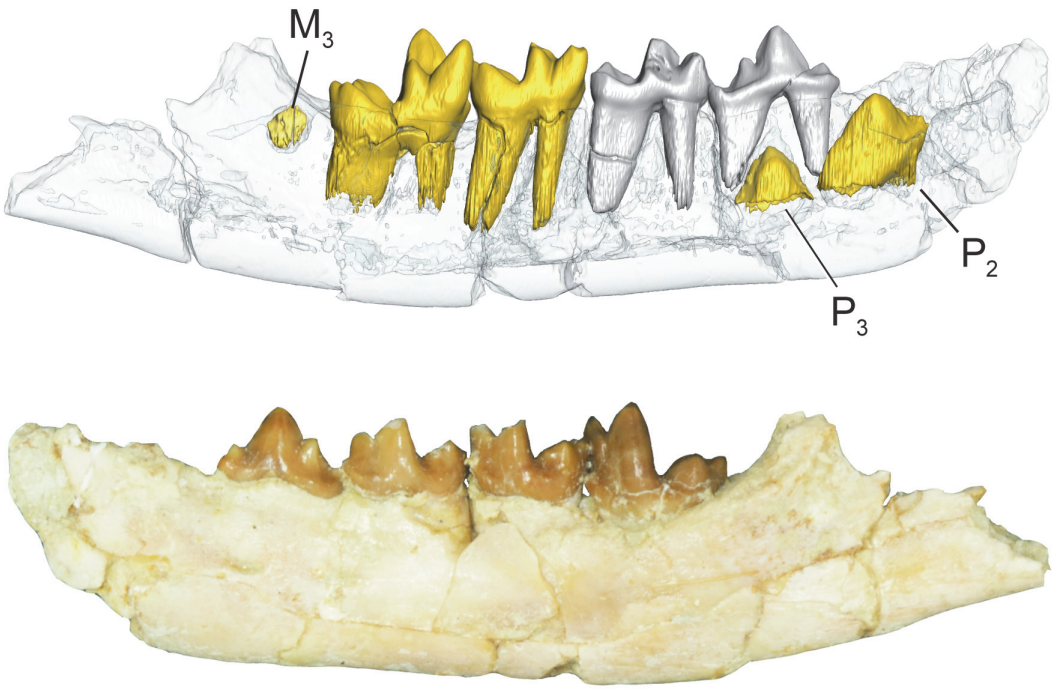

6

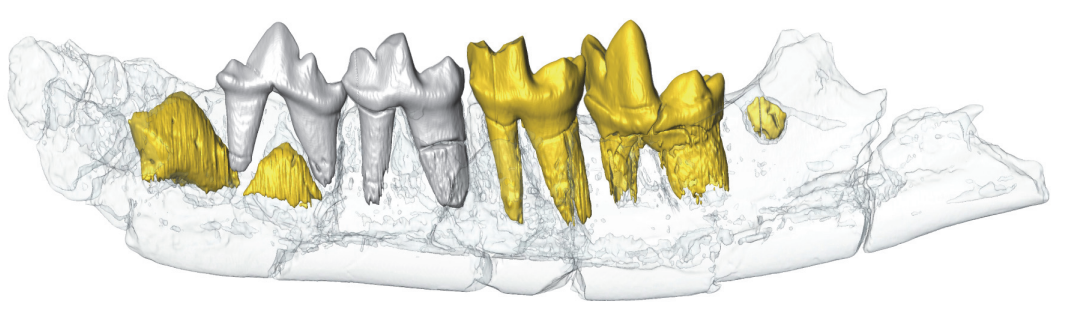

FIGURE 9. Masrasector nananubis left dentary with erupted $\mathrm{dP}_{3}, \mathrm{dP}_{4}, \mathrm{M}_{1}$ and $\mathrm{M}_{2}$ and $\mathrm{P}_{2}, \mathrm{P}_{3}$, and $\mathrm{M}_{3}$ in crypts (DPC 10358) from Locality 41 (latest Eocene), Fayum Depression, Egypt. Original specimen figured with digital model based on $\mu-C T$ scans reconstructed in Avizo. Dentary rendered transparent to reveal developing dentition. Grey, deciduous dentition. Yellow, permanent dentition. 1) specimen occlusal view; 2) model occlusal view; 3) specimen lingual view; 4) model lingual view; 5) specimen buccal view; 6) model buccal view. Scale bar is $10 \mathrm{~mm}$. 
the development of the permanent dentition revealed by $\mu-C T$. The dentary specimen DPC 18276 (Figure 8) preserves the crowns of the deciduous canine, $\mathrm{dP}_{2}, \mathrm{dP}_{3}, \mathrm{dP}_{4}$, and the alveoli of $M_{1}$. The developing buds of $P_{2}, P_{3}$, and $M_{2}$ are preserved in their crypts. Of these coalescing permanent teeth, $M_{2}$ is most advanced, with the enamel bells of the trigonid and talonid fully formed; it likely would have erupted before the other developing dentition. The $\mathrm{P}_{2}$ is framed by the roots of $\mathrm{dP}_{2}$. The crown of $\mathrm{P} 2$ is oriented oblique to the body of the dentary. A tiny portion of the differentiated enamel of the $P_{3}$ paraconid is visible between the roots of $\mathrm{dP}_{3}$. The dentary specimen DPC 10358 (Figure 9) is from a developmentally older individual than DPC 18276 (Figure 8). DPC 10358 preserves a fully erupted $M_{2}$, though the roots are not fully differentiated, the crown of $\mathrm{P}_{2}$ is nearly completely developed and it is oriented subparallel to the mandibular corpus, and $P_{3}$ is advanced into the enamel bell phase. Distal to $M_{2}$, a dense mass is visible in the $\mu$-CT scans, interpreted as the early differentiation of $M_{3}$. Neither Masrasector dentary specimen preserves any portion of the differentiated tooth bud of $\mathrm{P}_{4}$. Taken together, these specimens suggest the following order of permanent dental eruption in Masrasector nananubis: $\mathrm{M}_{1}, \mathrm{M}_{2}, \mathrm{P}_{2}, \mathrm{P}_{3}, \mathrm{M}_{3}$, and $\mathrm{P}_{4}$.

\section{Remarks}

Masrasector nananubis is much smaller than the other hyainailouroids discussed in this study. Whereas the metacone is immediately distal to the $\mathrm{dP}^{3}$ paracone in Anasinopa, Dissopsalis, and Leakitherium, the $\mathrm{dP}^{3}$ metacone in Masrasector nananubis is slightly lingually offset, a feature shared with Metasinopa. The metacone is lingually offset from the paracone even more dramatically on the $\mathrm{dP}^{4}$ of $M$. nananubis, a feature also shared with the teratodontines Brychotherium, Anasinopa, and Metasinopa, but not Dissopsalis. The lingually projecting protocone of the $\mathrm{dP}^{4}$ in $M$. nananubis frames a broad trigon basin, a feature also shared with Brychotherium, Anasinopa, and Metasinopa, but not with Dissopsalis (which exhibits a $\mathrm{dP}^{4}$ protocone that projects mesially and is not framed by the bases of both the metacone and paracone). This trigon basin diversity within Teratodontinae may reflect dietary differences within the clade, with Masrasector acting as a mesocarnivore and Dissopsalis acting as a hypercarnivore, though Dissopsalis retains some mesocarnivorous dental traits that help distinguish the taxon from the hyainailourids.

Genus METASINOPA Osborn, 1909

Type species. Metasinopa fraasi Osborn, 1909

Other included species. Metasinopa ethiopica Andrews, 1906; Metasinopa napaki Savage, 1965.

Metasinopa sp.

Figures 10-11, Tables 1-2

Referred specimens. DPC 10199, associated cranial fragments with $\mathrm{dP}^{3}, \mathrm{dP}^{4}, \mathrm{M}^{1}$ (Fayum Depression, Jebel Qatrani Formation, Quarry V); DPC 4544, $\mathrm{P}_{2}, \mathrm{dP}_{4}, \mathrm{M}_{1}-\mathrm{M}_{3}$ (Fayum Depression, Jebel Qatrani Formation, Quarry V). Note: The specimens were found in the same quarry, but are not likely associated with the same individual.

\section{Description}

The enamel on both $\mathrm{dP}^{3}$ and $\mathrm{dP}^{4}$ is smooth and thin (DPC 10199; Figure 10). The parastyle of $\mathrm{dP}^{3}$ is elongate and buccolingually compressed. The paracone of $\mathrm{dP}^{3}$ is the largest cusp on the tooth, with a paracone basal diameter twice the size of the basal diameter of the buccolingually

1

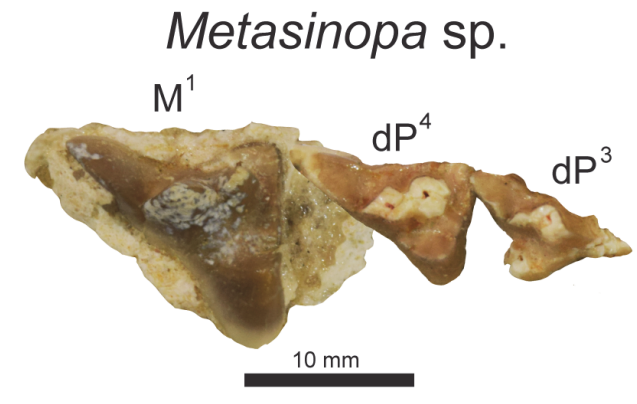

2

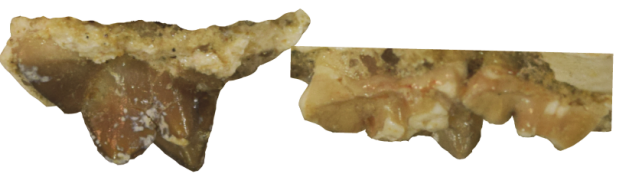

3

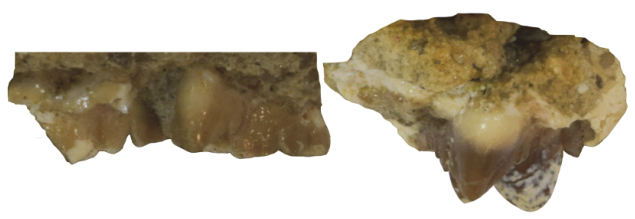

FIGURE 10. Metasinopa sp. left maxilla fragments with $\mathrm{dP}^{3}, \mathrm{dP}^{4}$, and $\mathrm{M}^{1}$ (DPC 10199) from Quarry $\mathrm{V}$ (early Oligocene), Fayum Depression, Egypt in 1) occlusal view; 2) buccal view; and 3) lingual view. Note that there is matrix around the roots of the specimens that has been cropped to make the dentition easier to view. Scale bar is $10 \mathrm{~mm}$. 


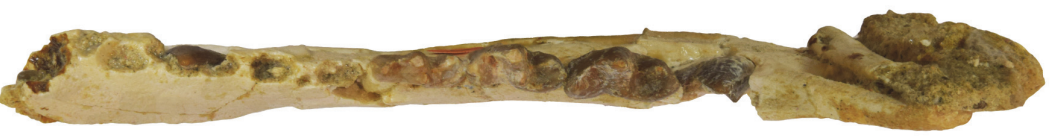

2

$\mathrm{P}_{1}$

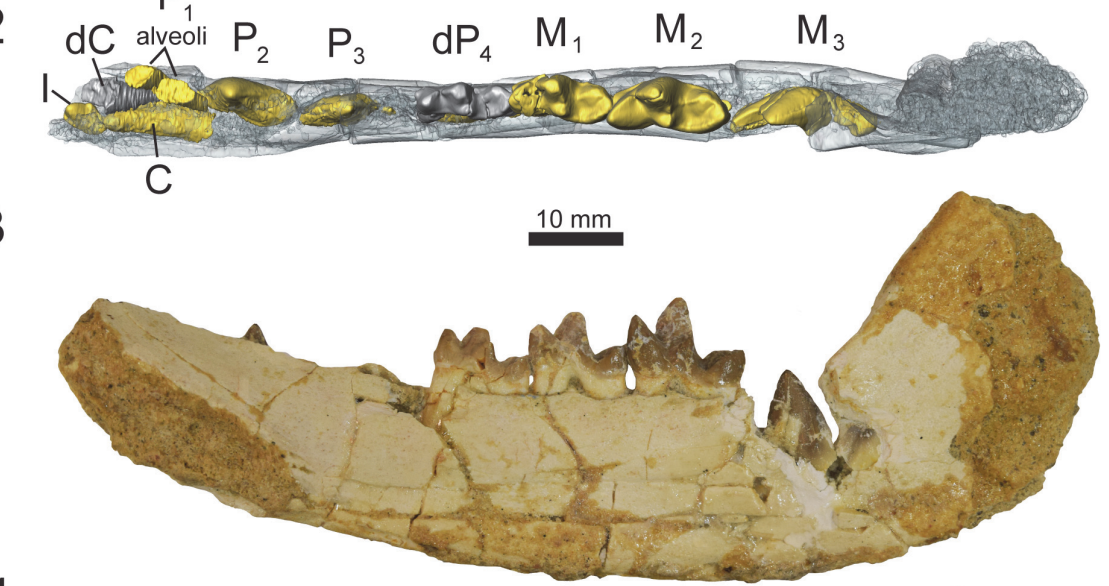

4

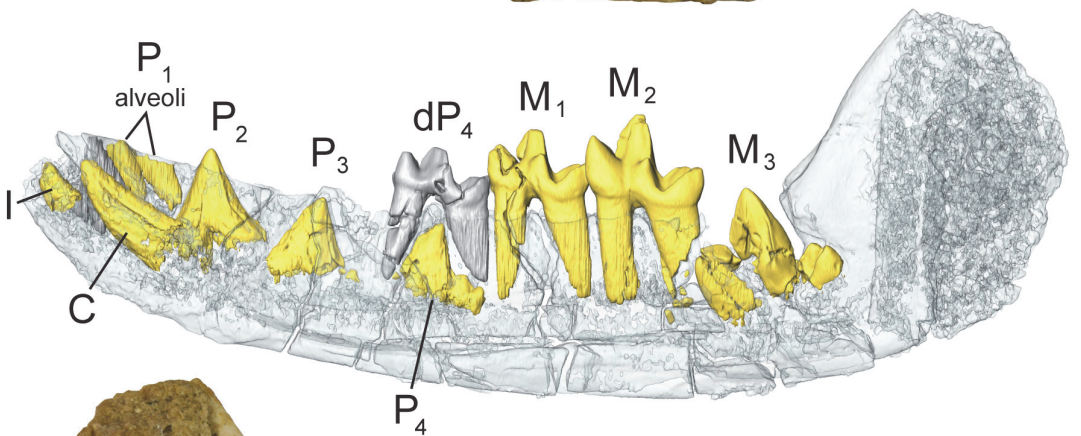

5

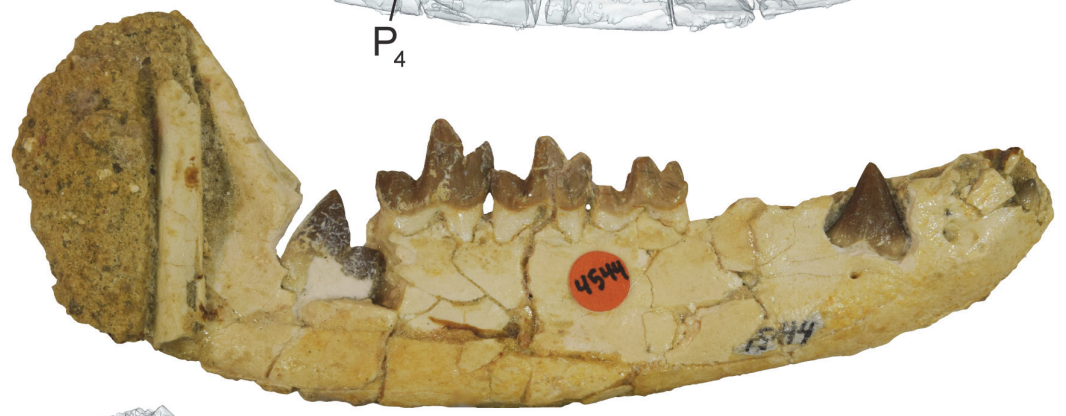

6

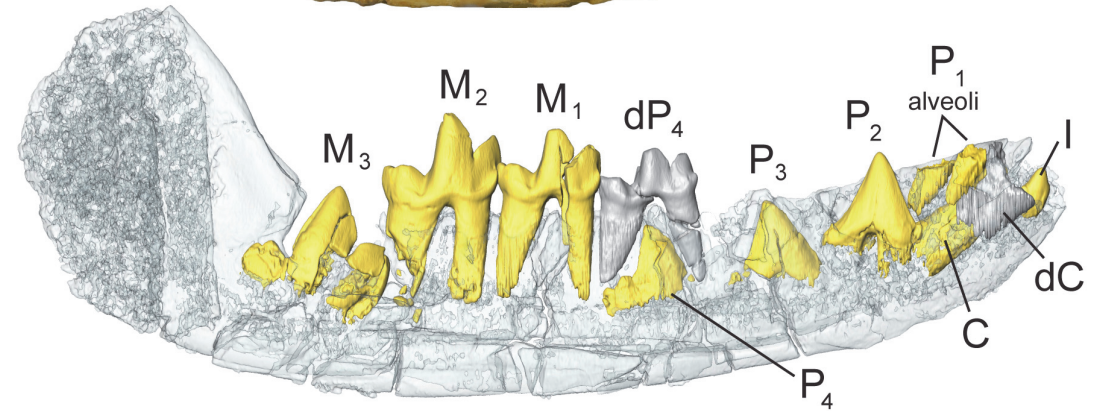

FIGURE 11. Metasinopa sp. right dentary with $\mathrm{dC}, \mathrm{dP}_{4}, \mathrm{M}_{1}, \mathrm{M}_{2}$ and $\mathrm{I}, \mathrm{C}, \mathrm{P}_{2}, \mathrm{P}_{3}, \mathrm{P}_{4} \mathrm{M}_{3}$ in crypts (DPC 4544) from Quarry $\vee$ (early Oligocene), Fayum Depression, Egypt. Original specimen figured with digital model based on $\mu$-CT scans reconstructed in Avizo. Dentary rendered transparent to reveal developing dentition. Grey, deciduous dentition. Yellow, permanent dentition. 1) specimen occlusal view; 2) model occlusal view; 3) specimen lingual view; 4) model lingual view; 5) specimen buccal view; and 6) model buccal view. Scale bar is $10 \mathrm{~mm}$. 
compressed metacone. The apex of the metacone is lightly worn and did not much exceed the maximum height of the metastyle. A very deep carnassial notch separates the metastyle from the metacone. The mesiodistal width of the protocone is subequal in diameter to the paracone. The protocone is isolated from the metastyle, but connected to the parastyle by a thin cingulum.

The $\mathrm{dP}^{4}$ exhibits a reduced parastyle compared to the $\mathrm{dP}^{3}$ and an elongate metastyle. The mesiodistal length of the $\mathrm{dP}^{4}$ metastyle is subequal to the mesiodistal diameter of the paracone and metacone base. Along the buccal margin of the metastyle is a shallow ectoflexus traced by a slight buccal cingulum. The apices of the paracone and metacone are not preserved, but the bases of these cusps indicate the paracone was conical and the metacone was more buccolingually compressed with a blade-like postmetacrista. The protocone of $\mathrm{dP}^{4}$ projects mesially and is nearly aligned with the mesial edge of the parastyle. The trigon basin is mesiodistally broad and framed by a distinct paraconule, metaconule and protocone.

In contrast to $\mathrm{dP}^{4}$, the mesiodistal length of the metacone of $\mathrm{M}^{1}$ is significantly longer than the base of the paracone, and the paracone is reduced to a mesially directed cusp that is lower than the metacone. The ectoflexus of $\mathrm{M}^{1}$ is deeper than the ectoflexus of $\mathrm{dP}^{4}$, and the buccal cingulum is thin to absent.

A dentary referable to Metasinopa (DPC 4544; Figure 11) was also discovered at Quarry V. The buccal portions of the dentary were prepared away, exposing the buccal faces $\mathrm{P}_{2}$ and $\mathrm{M}_{3}$. On the buccal aspect of the dentary, mental foramina are present inferior to the alveoli of both $P_{1}$ and $P_{2}$. The alveoli of $P_{1}$ indicate that the tooth had two roots and was aligned with the base of canine. The alveoli of $\mathrm{dP}_{3}$ are also preserved. The $\mathrm{dP}_{4}$ is buccolingually narrow compared with $M_{1}$, and the paraconid of $\mathrm{dP}_{4}$ is aligned with the protocone. This contrasts with the more lingually oriented paracone of $M_{1}$. A low metaconid is retained on $\mathrm{dp} 4$, a cusp also present, and at nearly the same absolute size, on each of the molars. The talonid of $\mathrm{dP}_{4}$ is closed lingually by a complete entocristid that connects to the base of the metaconid. The hypoconid is large and well developed, and the hypoconulid is a distinct distal cusp on the talonid. There is substantial wear on the protoconid and paraconid of $\mathrm{dP}_{4}$.
The $\mu$-CT scans reveal that all of the permanent dentition were present in DPC 4544 (Figure 11). A permanent incisor with three distinct tines is present mesial to the deciduous canine. The specimen does not preserve the complete incisor row, making it difficult to determine the precise incisor locus represented in this specimen. The incisor root is open, though the crown is complete. The permanent canine is developing in the crypt, lingual to the root of the deciduous canine. The crown of $\mathrm{P}_{2}$, both paraconid and talonid, and portions of the roots are fully developed and the apex of the tooth is preserved superior to the alveolar margin. The enamel crown of $\mathrm{P}_{3}$ is almost entirely differentiated in the crypt and the mesial root is partially coalesced, though portions of the talonid have not fully developed. The apex of $\mathrm{P}_{3}$ protrudes nearly to the alveolar margin. The crown and talonid of $\mathrm{P}_{4}$ are almost fully developed, though no portions of the roots have differentiated and the roots of $\mathrm{dP}_{4}$ are complete. Both $M_{1}$ and $M_{2}$ are erupted and $M_{3}$ is in the crypt with the trigonid and talonid fully developed, though the roots are undifferentiated. The crypt is recessed in the dentary and there is not enough space in the tooth row to fully accommodate the crown of $\mathrm{M}_{3}$, evidence that the body of the dentary had yet to elongate to accommodate the final lower molar. Given the development of each permanent tooth, the inferred eruption sequence for Metasinopa was likely: $M_{1}, M_{2}, P_{2}$, $P_{3}, M_{3}$, and $P_{4}$, then the canine with the mesial incisor erupting around the time of $\mathrm{P}_{2}$.

\section{Remarks}

Metasinopa has been assigned several species that range from the late Eocene through the Miocene of Afro-Arabia. The diagnoses of these species are in need of close examination (Lewis and Morlo, 2010), but we refer specimens from the early Oligocene of the Jebel Qatrani formation to Metasinopa based on comparisons with the lower dentition preserved in Metasinopa fraasi (Osborn, 1909). Slightly larger than Masrasector, Metasinopa exhibits more hypercarnivorous dental features than does Masrasector, including a reduced $\mathrm{dP}_{4}$ metaconid, more mesiodistally extensive metastyles on $\mathrm{dP}^{3}$ and $\mathrm{dP}^{4}$, and a taller, more buccolingually compressed metacone on $\mathrm{M}^{1}$. Metasinopa shares with Masrasector a slightly lingually placed metacone on $\mathrm{dP}^{3}$ and $\mathrm{dP}^{4}$ that divides the protocone from the metastyle, and a tall $\mathrm{dP}^{4}$ protocone that projects beyond the point of divergence 
between the metacone and paracone. Metasinopa shares with Brychotherium a deep ectoflexus on $\mathrm{dP}^{3}$ and $\mathrm{dP}^{4}$, not present in Masrasector or in the hyainailourids.

The $\mathrm{dP}_{4}$ of Metasinopa is relatively more buccolingually compressed than the $\mathrm{dP}_{4}$ of Masrasector with a narrower talonid relative to the trigonid. The $\mathrm{dP}_{4}$ metaconid of Metasinopa is relatively smaller than that of Masrasector, with former rising only slightly above the alveolar margin.

\section{PHYLOGENETIC ANALYSIS USING DECIDUOUS MORPHOLOGY}

\section{Phylogenetic Methods}

A phylogenetic analysis was conducted to incorporate the deciduous dental morphology described in this study into a larger analysis of hyaenodont relationships. Deciduous dental morphology is heritable in mammals (Hughes et al., 2000; Townsend et al., 2012) and is a rich source of phenotypic character information. The character-taxon matrix is an expansion of hyanodonts sampled by Borths et al. (2016), and Borths and Stevens (2017), building upon previous work by Polly (1996), Zack (2011), and Solé et al. (2014), adding additional characters of the deciduous dentition (14 deciduous, 148 total), and expanding the OTUs (84 total). Some of the characters incorporated into this analysis are modified from Bastl et al. (2014). The full character-taxon matrix used in this study is included as Appendix 1, with character descriptions and their references detailed in Appendix 2. Seventeen characters were ordered and are identified in Appendix 2.

This study incorporates deciduous dental material directly examined by the investigators. There is likely deciduous dental material that has been referred to one or more OTUs that were not scored for this particular analysis, particularly for OTUs from European localities. We included the taxa we were able to examine, and we invite later investigators to build upon this dataset with additional material referable to these taxa. Appendix 3 lists the specimens observed for each OTU as part of this study.

A model-based, Bayesian approach was used to analyze the character-taxon matrix in MrBayes (Ronquist et al., 2012) (Appendix 4). The goal of a Bayesian phylogenetic analysis is to recover a branch-length-scaled topology that maximizes the likelihood of observing the morphological character-taxon matrix. A Markov Chain Monte Carlo (MCMC) search explores different topologies with varying branch lengths, searching for optimal topologies given the dataset. Topologies are held or rejected depending on their probability in proportion to their likelihoods. All topologies that have been accepted compose the posterior distribution of trees, except for the first $25 \%$, which are rejected here as part of the burn-in period of the MCMC search. Posterior probabilities are proportional to the percentage of time the clade occurs in this posterior distribution. This method of phylogenetic inference has become commonplace in paleontological phylogenetic studies (e.g., Lee and Worthy, 2012; Gorscak et al., 2014; Herrera and Dávalos, 2016; Lund et al., 2016; Sallam and Seiffert, 2016; Turner et al., 2017; Argue et al., 2017).

We summarize the results in an "allcompat" summary tree that includes clades with both high and low support. In a strict consensus tree, a summary method for trees recovered through maximum parsimony analysis, clades resolved in all most parsimonious trees (MPTs) are illustrated, even if post-hoc support metrics reveal the clades have weak support. So too, an "allcompat" tree may reveal low posterior probability support for some clades, but these clades are not collapsed because the "allcompat" arrangement shows the most common arrangement of taxa at any given point in the tree. Conclusions drawn from weakly supported clades resolved in the Bayesian consensus tree should be treated cautiously, just as weakly supported clades in a strict consensus tree should be treated cautiously.

In this study, we used MrBayes 3.2.3 (Ronquist et al., 2012) to analyze the character-taxon matrix input file included as Appendix 4. The $M_{k}$ character model was used for morphological data, the data type was set to "standard" and the coding set "variable". The analysis was run over $10 \times 10^{6}$ generations with two runs performed simultaneously with four Markov chains. Three chains were heated (temp $=0.02)$ and the generations sampled every 1000 generations. The first $25 \%$ were discarded as part of the burn in period. Convergence was evaluated based on the effective sample size and average standard deviation of split frequencies for the final generation.

\section{Impact of Deciduous Dental Characters on Phylogenetic Inferences}

This analysis of hyaenodont relationships inferred using a Bayesian phylogenetic analysis incorporating deciduous dental characters is shown in Figure 12. It is summarized as an "allcompat" (majority-rule plus compatible groups) 


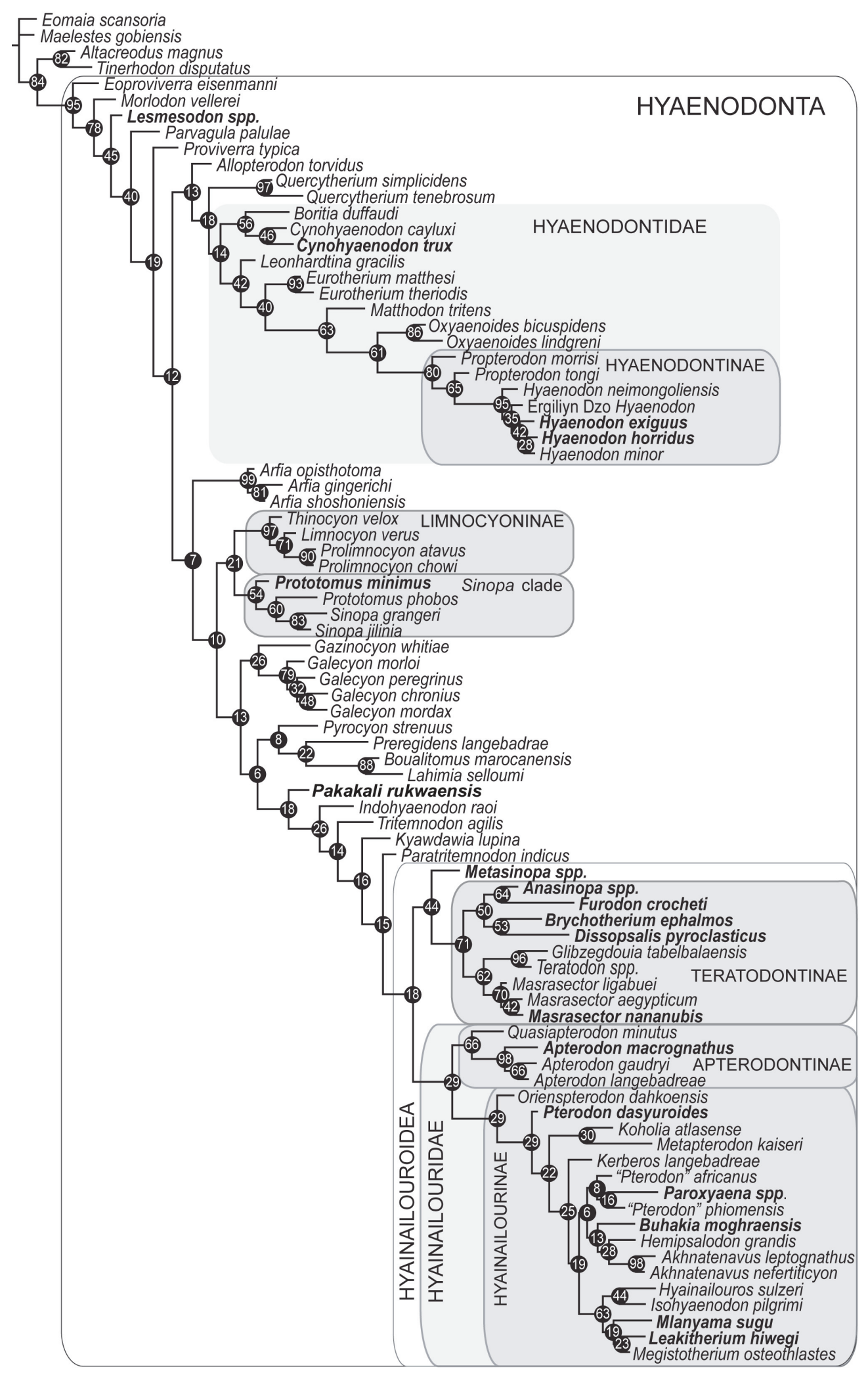

FIGURE 12. Results of the phylogenetic analysis of Hyaenodonta character-taxon matrix including deciduous dental characters. Results are visualized as an "allcompat" (majority rule plus compatible groups) consensus tree. Posterior probabilities (PP) are placed over each node. Bold taxa are scored for deciduous dental characters. Major, named clades recovered or discussed in this analysis and recovered in other analyses are illustrated. 
topology with posterior probabilities (PP) shown over the relevant node ("allcompat" tree with additional statistics included as Appendix 5). OTUs that have been scored for deciduous characters are indicated in bold, italicized font. Together with the Borths and Stevens (2017) analysis, this study documents the utility of deciduous dental characters in assessing phylogenetic relationships across hyaenodonts, significantly expanding upon ontogentic information previously available for just Hyaenodon (Bastl and Nagel, 2013). Recent work on hyaenodont systematics has improved sampling for Afro-Arabian OTUs (Borths et al., 2016), placing into context these descriptions of deciduous dentition from a broader sample of Afro-Arabian hyaenodonts.

\section{Description of Phylogenetic Results}

As in recent analyses (Borths et al., 2016; Borths and Seiffert, 2017; Borths and Stevens, 2017), our phylogenetic results suggest that the base of the hyaenodont radiation is joined by a sister clade composed of Altacreodus and Tinerhodon. These taxa have strong support as sister lineages $(P P=0.82)$ and the clade has strong support $(P P=0.84)$ as the sister clade of Hyaenodonta.

The earliest-diverging hyaenodont lineage in our study is Eoproviverra, diverging from a stem composed of European taxa. Along the hyaenodont stem is Lesmesodon, notably a taxon known almost exclusively from specimens that retain deciduous dentition. Proviverra is retrieved as the sister taxon of a clade that includes both hyaenodont lineages containing hypercarnivorous taxa: Hyaenodontidae and Hyainailouroidea. The clade that includes Hyaenodontidae incorporates three OTUs with referred deciduous dentition: Cynohyaenodon trux, Hyaenodon exiguus, and Hyaenodon horridus. C. trux forms a weakly supported clade with Cynohyaenodon cayluxi (PP = 0.46). $\mathrm{H}$. exiguus and $H$. horridus are nested within Hyaenodontinae $(P P=0.80)$ in the clade that includes all other Hyaenodon (PP $=0.95$ ) species.

The clade that includes Hyainailouroidea and all Afro-Arabian hyaenodonts is sister to the clade that includes Hyaenodontidae. Pakakali is resolved along the stem supporting Hyainailouroidea (PP = 0.18 ), though it should be noted this taxon is only known from $\mathrm{dP}^{3}$. Hyainailouroidea, the clade that includes Teratodontinae, Apterodontinae, and Hyainailourinae, is weakly supported $(P P=0.18)$. Within Hyainailouroidea, Metasinopa is weakly supported $(P P=0.44)$ as the sister-taxon of Terat- odontinae. Teratodontinae is moderately supported as a clade ( $P P=0.71)$. The group formed by Metasinopa and Teratodontinae includes several OTUs known from deciduous dental morphology including: Metasinopa, Anasinopa, Furodon, Brychotherium, and Masrasector nananubis. Anasinopa and Furodon are moderately supported in this analysis as sister-taxa $(P P=0.64)$ and weakly supported $(P P=0.50)$ as part of the same clade as Brychotherium and Dissopsalis. Masrasector nananubis is recovered within the strongly supported Masrasector clade $(\mathrm{PP}=0.70)$.

Hyainailouridae includes the moderately supported clade Apterodontinae $(P P=0.66)$ and the weakly supported clade Hyainailourinae $(\mathrm{PP}=$ 0.29). Within Apterodontinae Apterodon macrognathus is associated with deciduous dentition and has strong support within the clade Apterodon. Within Hyainailourinae, here resolved with Orienspterodon as the sister lineage of all other hyainailourines, several OTUs are known from deciduous dental morphology: Pterodon dasyuroides, Buhakia moghraensis, Paroxyaena, Mlanyama sugu, and Leakitherium. Pterodon dasyuroides is weakly supported $(P P=0.29)$ as the sister taxon of all more deeply nested hyainailourines. "Pterodon" africanus is the sister taxon of a very weakly supported clade $(P P=0.08)$ that includes Paroxyaena and "Pterodon" phiomensis $(P P=0.16)$. The Paroxyaena + "Pterodon" clade is weakly supported $(P P=0.06)$ as the sister clade of a clade that includes Buhakia, Hemipsalodon and Akhnatenavus. A more robustly supported Miocene hyainailourine clade $(\mathrm{PP}=0.63)$ is the sister clade of the Paroxyaena + Buhakia clade. The Miocene hyainailourine clade includes Hyainailouros sulzeri, Isohyaenodon pilgrimi, Mlanyama sugu, Megistotherium and Leakitherium hiwegi. In this analysis Leakitherium is weakly resolved (PP = 0.23 ) as the sister taxon of Megistotherium.

\section{Effect of Deciduous Dental Characters on Hyainailouroid Relationships}

With the specimens described here, we can now advocate for the use of deciduous dental characters in the reconstruction of systematic relationships among Afro-Arabian hyainailouroids. The inclusion of deciduous characters might be expected to have a confounding effect on phylogenetic resolution. Deciduous teeth have been hypothesized to retain plesiomorphic characters (Peterkova et al., 2006; Zack, 2012), hence their patchy inclusion might undermine recovery of the structure of phylogenetic relationships established 
with adult dental characters. For this reason, we tested the stability of hyaenodont relationships when dental characters were incorporated into the analysis and assessed whether deciduous dentition could be used to build phylogenetic hypotheses, or to make apomorphy-based diagnoses. This is especially important for taxa like Leakitherium, Paroxyaena pavlovi, Lesmesodon, Buhakia, and Pakakali that are known primarily from deciduous dental material.

Overall, the results of the Bayesian phylogenetic inference including deciduous materials are broadly congruent with the results of the standard Bayesian analysis presented by Borths and Seiffert (2017) for strictly permanent dentition. In particular, taxa retrieved in Hyainailourinae, Apterodontinae, Teratodontinae, and Hyaenodontidae by Borths and Seiffert (2017) were retrieved in similar positions in this study. A difference between the Borths and Seiffert (2017) topology and the present study is the support resolved at the nodes supporting Hyainailouroidea, which are generally weaker when deciduous dental characters and accompanying missing data for many OTUs are included. In both studies, the most likely topologies are similar, but the support for nodes along the stem of Hyainailouroidea and supporting Teratodontinae + Hyainailouridae are weaker. Nonetheless, including deciduous dentition makes it possible to include taxa known primarily from deciduous materials (e.g., Lesmesodon or Pakakali). With the recovery and description of additional deciduous and adult specimens, resolution and support can be expected to improve along with the application of different phylogenetic methods, such as Bayesian "tip-dating" analysis (Beck and Lee, 2014).

\section{RECONSTRUCTING DENTAL ERUPTION SEQUENCE AND IMPLICATIONS}

\section{Dental Eruption Assessment}

To reconstruct the order of dental eruption in Hyainailouroidea, we studied multiple isolated specimens in different phases of development. We determined the order of premolar and molar eruption by examining relative tooth wear on adult and deciduous dentition and by examining specimens with tooth germs preserved in the crypt that could be $\mu$-CT scanned at Duke University. Tooth germs in a more advanced stage of development than another germ preserved in the same specimen are considered likely to erupt before the less developmentally advanced germ. This method of identifying an eruption sequence from multiple individuals follows the efforts of Slaughter et al. (1974), Smith (2000), Anders et al. (2011), Zack (2012), and Bastl and Nagel (2013).

\section{Dental Eruption Sequence in Hyainailouroidea} Compared with Other Hyaenodonts

A number of studies of mammalian evolution have explored the dental eruption sequence as a guide for both phylogenetic and developmental hypotheses (Bryant, 1988, 1990; Smith, 2000; Koufos and de Bonis, 2004; Henderson, 2007; Hughes et al., 2007; Asher and Lehmann, 2008; Asher et al., 2017). Based on the materials described in this study, we can now formulate a hypothesis for the order of dental eruption and replacement in Afro-Arabian hyainailouroids. The dental eruption sequence of hyainailouroids can then be compared with the eruption sequences of carnivorous mammals with better known developmental histories (Table 3). Note that there is variation in the dental eruption sequence within different clades of mammals (e.g., Henderson, 2007; Monson and Hlusko, 2016; Asher et al., 2017), and the eruption sequences of different clades of hyaenodonts may emerge as highly variable as more data are collected using scans of the internal anatomy of dentally immature specimens.

For the upper dentition, Borths et al. (2016) described a specimen of the teratodontine Brychotherium (DPC 17627) that preserved a fully erupted $\mathrm{P}^{4}$ on the right side and a worn $\mathrm{dP}^{4}$ on the left side, evidence that DPC 17627 died during the developmental interval when $\mathrm{dP}^{4}$ is replaced by its adult counterpart. On the left side, distal to $\mathrm{dP}^{4}$, are $\mathrm{M}^{1}$, $M^{2}$, and $M^{3}$, evidence that all molars were present before the eruption of $\mathrm{P}^{4}$. Unfortunately this specimen does not preserve $\mathrm{dP}^{3}, \mathrm{P}^{3}$, or the germ of $\mathrm{P}^{3}$, making it difficult to determine if $\mathrm{P}^{3}$ erupted before $\mathrm{P}^{4}$, coincident with the eruption of $\mathrm{P}^{4}$ or after $\mathrm{P}^{4}$. KNM-RU 15182 (Figure 3) is a maxillary fragment of the hyainailourine Leakitherium that preserves $\mathrm{P}^{4}$ in the crypt above the roots of $\mathrm{dP}^{4}$. In this specimen, the crown of $\mathrm{dP}^{3}$ is preserved but no evidence of $\mathrm{P}^{3}$ is present in the crypt, indicating that $\mathrm{P}^{4}$ may have been more fully developed than $\mathrm{P}^{3}$. In Masrasector nananubis (DPC 13837, Figure 7) the developmental sequence is flipped, with $\mathrm{P}^{3}$ more fully developed than $\mathrm{P}^{4}$. This difference may indicate some variability in the eruption of these premolars in hyainailouroids. No specimens included in this study preserve the upper canines or incisors and $\mathrm{dP}^{2}$ is only known from a specimen of Anasinopa (KNM-RU 2385), which does not preserve the 
TABLE 3. Dental eruption sequences of Hyaenodonta and Ferae. Upper and lower eruption sequences are separated for this study because no hyainailouroid specimen directly reveals the relationship between the timing of eruption in the upper and lower dentition. Sequence reads from left to right with m-dashes identifying subsequent events. Tooth positions contained in parentheses are unknown. Tooth positions with an asterisk are variable within the group. Note that taxa listed in "Group" are not all the same taxonomic level.

\begin{tabular}{|c|c|c|c|}
\hline Group & Eruption of Upper dentition & Eruption of lower dentition & Reference \\
\hline Hyainailouroidea synthesis & $\mathrm{M}^{1}-\mathrm{M}^{2-} \mathrm{M}^{3-} \mathrm{P}^{4}$ or $\mathrm{P}^{3}\left(\mathrm{P}^{2}, \mathrm{C}\right)$ & $\mathrm{M}_{1}-\mathrm{M}_{2}-\mathrm{P}_{2}-\mathrm{P}_{3}-\mathrm{M}_{3}-\mathrm{P}_{4}-\mathrm{C}$ & This study \\
\hline Apterodon macrognathus & & $\mathrm{M}_{1}-\mathrm{M}_{2}$ & This study \\
\hline Masrasector nananubis & $M^{1}-?-?-P^{3}-P^{4}$ & $\mathrm{M}_{1}-\mathrm{M}_{2}-\mathrm{P}_{2}-\mathrm{P}_{3}-\mathrm{M}_{3}-\mathrm{P}_{4}-\mathrm{C}$ & This study \\
\hline Metasinopa & & $\mathrm{M}_{1}-\mathrm{M}_{2}-\mathrm{P}_{2}-\mathrm{P}_{3}-\mathrm{M}_{3}-\mathrm{P}_{4}-\mathrm{C}$ & This study \\
\hline Brychotherium ephalmos & $M^{1}-M^{2-} M^{3-} P^{4}$ & & This study \\
\hline Leakitherium hiwegi & ?P4_-P3 & & This study \\
\hline North American Hyaenodon & $M^{1}-I-P^{2}-P^{4}-M^{2}-P^{3}-C$ & $\mathrm{M}_{1}-\mathrm{M}_{2-} \mathrm{I}-\mathrm{P}_{2-} \mathrm{P}_{4-} \mathrm{M}_{3-} \mathrm{P}_{3-} \mathrm{C}$ & $\begin{array}{l}\text { Bastl and Nagel, } \\
2013\end{array}$ \\
\hline European Hyaenodon & $\mathrm{M}^{1}-\mathrm{P}^{1}-\mathrm{I}-\mathrm{P}^{2}-\mathrm{P}^{4}-\mathrm{M}^{2}-\mathrm{P}^{3}-\mathrm{C}$ & $\mathrm{M}_{1-} \mathrm{P}_{1-} \mathrm{M}_{2-}-\mathrm{I}_{2-} \mathrm{C}, \mathrm{P}_{3}, \mathrm{M}_{3-} \mathrm{P}_{4}$ & $\begin{array}{l}\text { Bastl and Nagel, } \\
2013\end{array}$ \\
\hline Lesmesodon & $\mathrm{I}-\mathrm{P}^{1}-\mathrm{M}^{1}-\mathrm{M}^{2}-\mathrm{C}-\mathrm{P}^{2}$ & $\mathrm{I}-\mathrm{P}_{1}-\mathrm{M}_{1}-\mathrm{M}_{2}-\mathrm{C}-\mathrm{P}_{2}$ & $\begin{array}{l}\text { Morlo and } \\
\text { Habersetzer, } 1999\end{array}$ \\
\hline Oxyaena woutersi & & $M_{1}-P_{4}-P_{2}-P_{3}\left(M_{2}\right)$ & Solé et al., 2011 \\
\hline Didymictis protenus & $\mathrm{M}^{1}-\mathrm{P}^{2} / \mathrm{P}^{3} / \mathrm{P}^{4}$ & $\mathrm{P}_{2} / \mathrm{M}_{1} / \mathrm{M}_{2}-\mathrm{P}_{3} / \mathrm{P}_{4}$ & Zack, 2012 \\
\hline Viverridae & $\mathrm{M}^{1}-\mathrm{P}^{4}-\mathrm{P}^{2 *}-\mathrm{P}^{3}-\mathrm{M}^{2 *}$ & $\mathrm{M}_{1-} \mathrm{M}_{2-} \mathrm{P}_{2}{ }^{*}-\mathrm{P}_{3-} \mathrm{P}_{4}$ & Slaughter et al., 1974 \\
\hline Felidae & $\mathrm{P}^{2} / \mathrm{M}^{1}-\mathrm{P}^{4}-\mathrm{P}^{3}$ & $\mathrm{M}_{1} \mathrm{P}_{4-} \mathrm{P}_{3}$ & Slaughter et al., 1974 \\
\hline Mustelidae & $M^{1}-P^{4}-P^{2}-P^{3}$ & $\mathrm{M}_{1-} \mathrm{M}_{2-} \mathrm{P}_{2}{ }^{*}-\mathrm{P}_{3-} \mathrm{P}_{4}$ & Slaughter et al., 1974 \\
\hline Canidae & $\mathrm{M}^{1}-\mathrm{M}^{2}-\mathrm{P}^{4}-\mathrm{P}^{2}-\mathrm{P}^{3}$ & $\mathrm{M}_{1} / \mathrm{M}_{2}-\mathrm{M}_{3}{ }^{*}-\mathrm{P}_{2}{ }^{*}-\mathrm{P}_{4-} \mathrm{P}_{3}$ & Slaughter et al., 1974 \\
\hline
\end{tabular}

relationship between $\mathrm{P}^{2}$ eruption and molar eruption, leaving the timing of the replacement of these teeth in hyainailouroids unresolved. Based on this information, the order of upper dental eruption in hyainailouroids is:

$$
\begin{gathered}
\mathrm{M}^{1}-\mathrm{M}^{2}-\mathrm{M}^{3}-\mathrm{P}^{3} \text { or } \mathrm{P}^{4}\left(\mathrm{P}^{2}, \mathrm{C}, \mathrm{I}\right. \text { eruption } \\
\text { unresolved }) \\
\text { Equation } 1
\end{gathered}
$$

The eruption sequence for the lower dentition of Hyainailouroidea is better known and can be inferred particularly from specimens of Masrasector nananubis (DPC 18276, Figure 8; DPC 10358, Figure 9), Metasinopa (DPC 4544, Figure 11), and Buhakia (DPC 8994; Morlo et al., 2007, figure 2). In Masrasector and Metasinopa $\mathrm{M}_{2}$ erupted before the premolars and canine. In both taxa $P_{2}$ is the most developed premolar, evidence it was the first permanent premolar to erupt, followed by $\mathrm{P}_{3}$. The dentary specimen of Metasinopa (DPC 4544, Figure 11) preserves $M_{3}$ near the alveolar margin and more developed than $\mathrm{P}_{4}$. Of the permanent dentition preserved in DPC 4544, the canine is the least developed, likely making it the last permanent tooth in the dentary. Based on this information the order of lower dental eruption in hyainailouroids is:

$$
\begin{gathered}
\mathrm{M}_{1}-\mathrm{M}_{2}-\mathrm{P}_{2}-\mathrm{P}_{3}-\mathrm{M}_{3}-\mathrm{P}_{4}-\mathrm{C} \\
\text { Equation } 2
\end{gathered}
$$

Morlo et al. (2007) described the left dentary of Buhakia moghraensis, and they identified the preserved crowns as $\mathrm{dP}_{4}, \mathrm{M}_{1}$, and $\mathrm{M}_{2}$. They also interpreted alveoli on the specimen as evidence of $\mathrm{dP}_{3}$ and $\mathrm{dP}_{2}$. We concur with this interpretation, as $\mathrm{M}_{2}$ had recently erupted in the holotype of Buhakia and DPC 4544 (Metasinopa) shows $\mathrm{dP}_{2}$ was not replaced until $M_{2}$ was fully erupted. Solé et al. (2016) also identified a dentary fragment of the Afro-Arabian hyaenodont, Parvavorodon (CBI-163), with the alveoli of $\mathrm{dP}_{3}$, the crowns of $\mathrm{dP}_{4}$, and $M_{1}$, and the alveoli of $M_{2}$. Based on a CT-scan of the specimen, they determined the germs of $\mathrm{P}_{3}$ and $\mathrm{P}_{4}$ had not yet formed in the crypts below $\mathrm{dP}_{3}$ and $\mathrm{dP}_{4}$ despite the presence of $\mathrm{M}_{2}$. This suggests Parvavorodon differs from Masrasector nananubis developmentally as one specimen of Masrasector (DPC 18276, Figure 8) preserves the germs of $P_{2}$, 
$P_{3}$, and $M_{2}$ each developing in their crypts contemporaneously.

In Hyaenodon, Bastl and Nagel (2013) reconstructed North American Hyaenodon with the upper dental eruption sequence $\mathrm{M}^{1}-\mathrm{I}-\mathrm{P}^{2}-\mathrm{P}^{4}-\mathrm{M}^{2}$ $P^{3}-C$ and lower dental eruption sequence $M_{1}-M_{2}-$ $\mathrm{I}-\mathrm{P}_{2}-\mathrm{P}_{4}-\mathrm{M}_{3}-\mathrm{P}_{3}-\mathrm{C}$. European Hyaenodon is reconstructed with the upper eruption sequence $\mathrm{M}^{1}-\mathrm{P}^{1}-\mathrm{I}-\mathrm{P}^{2}-\mathrm{P}^{4}-\mathrm{M}^{2}-\mathrm{P}^{3}-\mathrm{C}$ and $\mathrm{M}_{1}-\mathrm{P}_{1}-\mathrm{M}_{2}-\mathrm{I}^{-} \mathrm{P}_{2}-$ $C, P_{3}, M_{3}-P_{4}$. The lower eruption sequence of hyainailouroids is most like the lower eruption sequence of European Hyaenodon, with $\mathrm{M}_{3}$ erupting before the emergence of $\mathrm{P}_{4}$. The upper eruption sequence of hyainailouroids differs from the reconstructed sequence in both European and North American Hyaenodon. In Hyaenodon, P4 emerges before $\mathrm{M}^{2}$. In Brychotherium $\mathrm{M}^{2}$ is already erupted when $\mathrm{P}^{4}$ is being replaced and $\mathrm{M}^{3}$ is emerging.

With multiple specimens of Lesmesodon, Morlo, and Habersetzer (1999) reconstructed the partial eruption sequence of this Eocene hyaenodont known almost exclusively from dentally immature individuals found in the Messel Pit in Germany. Like hyainailouroids, Lesmesodon replaced $\mathrm{dP}_{2}$ after the eruption of $M_{1}$ and $M_{2}$. Lesmesodon is consistently resolved as part of an early-diverging lineage (Borths et al., 2016; Borths and Seiffert, 2017) with other European mesocarnivorous hyaenodonts that have been allied with "Proviverrinae" (Solé et al., 2014). This phylogenetic position supports the Lesmesodon eruption sequence $\left(\mathrm{P}_{2}\right.$ erupted after $\mathrm{M}_{2}$ ) as the ancestral condition in Hyaenodonta.

\section{Dental Eruption Sequence of Hyaenodonta Compared with Other Carnivorous Mammals}

Traditionally, Hyaenodonta is allied with Oxyaenidae in "Creodonta" and "Creodonta" is placed within Ferae, the clade that includes Pholidota and Carnivora (Rose, 2006). This phylogenetic hypothesis collects most placental mammals with specialized carnassials in the same clade (Spaulding et al., 2009; O'Leary et al., 2013; Halliday et al., 2015). As summarized by Rana et al. (2015) and Borths et al. (2016), these relationships-including the sister-clade relationship between hyaenodonts and oxyaenids-require further phylogenetic testing.

The dental eruption sequence of Oxyaena woutersi was partially reconstructed by Solé et al.
(2011) based on MNHN QNY2-2527 as $\mathrm{M}_{1}-\mathrm{P}_{4}-$ $P_{2}-P_{3}$. The specimen preserves neither $M_{2}$, nor its alveoli, making it difficult to determine whether the premolars were replaced before or after the terminal molar erupted. Regardless, the eruption of $\mathrm{P}_{4}$ before the eruption of $P_{2}$ and $P_{3}$ is different from all hyaenodont eruption sequences known. This difference may support the hypothesis that hyaenodonts and oxyaenids converged on dentition specialized for carnivory, and may not be sister clades (Polly, 1996) in Ferae nor form a monophyletic Creodonta.

The order of dental eruption differs within Carnivora. Slaughter et al. (1974) observed that Mustelidae and Viverridae, two distantly related carnivoran clades that contain mesocarnivorous taxa, share eruption sequences: $\mathrm{M}^{1}-\mathrm{P}^{4}-\mathrm{P}^{2 *}-\mathrm{P}^{3}-$ $M^{2} ; M_{1}-M_{2}-P_{2}-P_{3}-P_{4}$. Slaughter et al. (1974) noted that the eruption of $\mathrm{P}^{2}, \mathrm{P}_{2}$, and $\mathrm{M}^{2}$ (when present) is variable but in both groups, $P_{3}$ is replaced before $\mathrm{P}_{4}$, a pattern also observed by Bastl and Nagel (2013) in Hyaenodon and in this study in Masrasector and Metasinopa.

In contrast to Mustelidae and Viverridae, in Canidae and Felidae $P_{4}$ erupts before $P_{3}$. Slaughter et al. (1974) suggested this may represent an adaptation in two distantly related clades to preserve the deciduous carnassial formed between $\mathrm{dP}^{3}$ and $\mathrm{dP}_{4}$ until after the full eruption and occlusion of $\mathrm{P}^{4}$ and $\mathrm{M}_{1}$ has taken place. This developmental convergence highlights the importance of a functioning carnassial in carnivorans. A key morphological difference between Carnivora and Hyaenodonta is that in Carnivora, an individual only develops two carnassials through the course of its lifetime. In hyaenodonts, an individual develops four: $\mathrm{dP}^{3} / \mathrm{dP}_{4}, \mathrm{P}^{4} / \mathrm{M}_{1}, \mathrm{M}^{1} / \mathrm{M}_{2}$, and $\mathrm{M}^{2} / \mathrm{M}_{3}$. European Hyaenodon follows the hypercarnivorous pattern by delaying the replacement of the deciduous carnassial until the final carnassial complex is formed between $M^{2} / M_{3}$, suggesting that even in a lineage with multiple carnassials, there was selective pressure to preserve the deciduous carnassial as long as possible. Similarities in the dental eruption sequence do not refute a possible relationship between Carnivora and Hyaenodonta. Significant differences between the clades, however, do raise the question of how in each case the dental eruption sequence interfaces with the development of the rest of the animal. 


\section{What Does the Timing of Tooth Eruption Tell Us about Hyainailouroids?}

In many carnivorans it only takes up to one year for the adult dentition to fully erupt (Miles and Grigson, 1990). In contrast, Bastl and Nagel (2013) demonstrated through enamel studies that Hyaenodon took between three and four years to develop its adult dentition, implying either that hyaenodonts developed more slowly overall than carnivorans, or that dental replacement was decoupled from the skeletal and cranial development such that dentally immature hyaenodont individuals may have been reproductively mature.

The "developmental decoupling" hypothesis is supported by a cranial specimen of Paroxyaena pavlovi described by Lavrov (2007). Lavrov (2007) noted that the specimen retains $\mathrm{dP}^{3}$ and $\mathrm{dP}^{4}$, but already has the well-sutured cranial vault of a mature individual. Notably, Paroxyaena retained a functional $\mathrm{dP}^{3} / \mathrm{dP}_{4}$ carnassial complex at an adult body size. Brychotherium also exhibits an adultsized rostrum with $\mathrm{dP}^{4}$ still in the maxilla as $\mathrm{M}^{3}$ erupted. This extended dental developmental interval would have allowed these hyainailouroids to wear the deciduous carnassial for up to three extra years, a significantly longer interval compared with carnivorans. When $\mathrm{P}^{3}$ and $\mathrm{P}_{4}$ finally erupted, they erupted into a fully mature dentary and were spared from years of accumulated wear, wear that is preserved on the $\mathrm{dP}_{4}$ of Metasinopa (DPC 4544) and $\mathrm{dP}^{3}$ of Pakakali (Borths and Stevens, 2017).

Modern carnivorans can break their teeth while capturing and processing their prey (Van Valkenburgh, 1988; Binder and Van Valkenburgh, 2010), evidence that risk of damage to the permanent dentition may act as a selective pressure upon tooth morphology and replacement. Exceeding the safety factors that lead to tooth breakage is not common (Van Valkenburgh, 1988), indicating morphological and behavioral adaptations tend to prevent it, but the abrasion of teeth is less preventable on an individual level in carnivorans and is so constant a pressure that the metric can be used to age carnivorans in the field (e.g., White and Belant, 2016; Chevallier et al., 2017). Binder and Van Valkenburgh (2000) observed that in hyenas, there is a shift in tooth use with age from mesial deciduous premolars to distal adult premolars. Binder and Van Valkenburgh (2000) hypothesized this shift could serve to protect the single carnassial pair. Ultimately, these studies demonstrate that shearing crest preservation may be a selective pressure for carnivorous mammals. By delaying the replace- ment of the deciduous carnassial and erupting permanent carnassial pairs while the deciduous carnassial was active, hyaenodonts preserved their ability to access vertebrate prey throughout their lives, guarding against breakage and excessive wear.

One strange aspect of the hyaenodont fossil record is the abundance of dentally immature specimens. Every specimen of Lesmesodon collected from Messel preserves deciduous dentition. Of the three known maxilla fragments of Leakitherium, two preserve $\mathrm{dP}^{3}$ and $\mathrm{dP}^{4}$. The holotype of Mlanyama sugu preserves $\mathrm{dP}_{4}$. We suggest that if dental development occurred over a longer temporal duration in hyaenodonts than in, for example, carnivores, it would be increasingly likely for immature individuals to be preserved in the fossil record, and this might explain a relatively high number of specimens preserving deciduous teeth in this clade.

The early ontogeny of mammals is not generally the phenotype used to interpret the ecological position of a taxon. In carnivorans, dentally immature individuals are usually less than a year old, hence it is justifiable to focus on a dentally mature individual as the phenotype that natural selection is primarily acting upon. This is defined by Anders et al. (2011) as individual dental age stage (IDAS) 3adult. But in hyaenodonts, the phenotype interacting with the environment for multiple years was IDAS 2 (juvenile). Delayed eruption of adult dentition has also been noted by Asher and Lehmann (2008) and Asher et al. (2017) for the clade Afrotheria. Although interesting, any implications of that similarity are beyond the scope of this study. The Pleistocene bovid Myotragus balearicus (Jordana and Köhler, 2011) also extended the period of dental development relative to its body size, a shift the authors suggest may have been related to the resource-poor island habitat occupied by $M$. balearicus. Perhaps shifts in hyainailouroid life history and dental development reflect changes in resource availability related to environmental changes in the Paleogene-Neogene of Afro-Arabia.

To date, most ecological comparisons between carnivorans and hyaenodonts have been based upon the adult phenotypes of both groups. This is understandable, as both share similar dental eruption sequences, both have specialized carnassials, and both exhibit postcranial adaptations for carnivory. Yet hyainailouroids appear to have employed a different ontogenetic timing strategy from Carnivora, hence future hypotheses to explain 
the success of Carnivora and the extinction of Hyaenodonta should address developmental differences between the two most diverse carnivorous mammalian lineages of the Cenozoic. Indeed, additional research is needed to account for life history metrics such as the rate of tooth growth (Smuts et al., 1978), the development of the pulp cavity (Meachen-Samuels and Binder, 2010), and the inference of growth rates from long bones (Kolb et al., 2015) as potential sources of data in exploring the differences between carnivoran and hyaenodont ontogeny.

\section{CONCLUSIONS}

Deciduous dental morphology has been underutilized in the larger effort to understand hyaenodont biology. In this study, we describe specimens referred to six different species of Hyainailouroidea, the hyaenodont clade that contains the majority of Afro-Arabian hyaenodonts. We demonstrate that phylogenetically informative character information is preserved in deciduous dental morphology, and that these characters can be used to explore hyaenodont relationships. Based on the specimens described herein, we reconstruct the dental eruption sequence of hyainailouroid hyaenodonts. The dental eruption sequence is a rich source of additional systematic insight in the ongoing effort to understand the placental tree of life. Correlating the dental eruption sequence of Hyainailouroidea with cranial development, we suggest that hyaenodonts in Afro-Arabia and in Eurasia exhibited an extended period of dental eruption. Delayed dental replacement in hyaenodonts allowed these carnivorous mammals to spread carnassial wear across the tooth row, and freed hyaenodonts from dependence on a single, functional permanent pair carnassial. In contrast, Carnivora quickly erupts the adult dentition and is limited to one pair of carnassials on each side of the mouth that must survive throughout the individual's life. Understanding the deciduous dentition of hyaenodonts is essential for understanding both the higher-order relationships of the group, and for understanding the biology of this widespread and morphologically diverse radiation of carnivorous mammals.

\section{ACKNOWLEDGMENTS}

We dedicate this project to the memory of Gregg F. Gunnell: mentor, friend, and fossil hunter. We thank the Egyptian Mineral Resources Authority and the Egyptian Geological Museum for facilitating fieldwork in the Fayum area, P. Chatrath for managing fieldwork, and multiple Fayum field crews for the efforts in excavating the Fayum area. We also thank the National Commission for Science, Technology and Innovation in Kenya and the National Museums of Kenya for facilitating specimen access in Kenya. Scanning assistance at Duke University was provided by $\mathrm{H}$. Sallam and S. Heritage and imaging assistance at the University of Southern California was provided by B. Patel and E. Seiffert. Imaging assistance at Ohio University was provided by K. Brock, J. Piurowski, B. Sanders, S. Travis, and S. Aftabizadeh. We thank the many curators and collections managers who have coordinated access to their collections including C. Argot and G. Billet (Muséum National d'Histoire Naturelle, Paris), M. Brett-Surman (National Museum of Natural History, Washington, D.C), P. Brewer (Natural History Museum, London), L. Costeur (Naturhistorisches Museum, Basel), J. Chupasko and J. Cundiff (Museum of Comparative Zoology, Cambridge), J. Galkin (AMNH), G. Gunnell (DPC), M. Hellmund (Geiseltal Museum, Halle), J. Hooker (Natural History Museum, London), A. Lavrov (Paleontological Institute, Moscow), E. Mbua, F. Manthi, M. Muungu, and F. Ndiritu (KNM), C. Norris (Yale Peabody Museum, New Haven), S. Pierce (Museum of Comparative Zoology, Cambridge), T. Smith (Institut royal des Sciences naturelles de Belgique, Brussels), $\mathrm{S}$. Schaal (SMF), F. Solé (Institut royal des Sciences naturelles de Belgique, Brussels), B. Sanders (University of Michigan, Ann Arbor), G. Rössner (BSPG), A. Sileem (CGM), A. Vogal (Naturmuseum Senckenberg, Frankfurt am Main), E. Westwig (AMNH), N. Xijun (Institute for Vertebrate Paleontology and Paleoanthropology, Beijing), and R. Ziegler (SMNS) for specimen access. Funding by: The Explorers Club, the Society for Integrative and Comparative Biology, and the National Science Foundation (BCS- 1638796; DEB-1311354; DBI- 1612062).

\section{REFERENCES}

Anders, U., von Koenigswald, W., Ruf, I., and Smith, B.H. 2011. Generalized individual dental age stages for fossil and extant placental mammals. Paläontologische Zeitschrift, 85:321339. https://doi.org/10.1007/s12542-011-0098-9 
Andrews, C.W. 1904. Further notes on the mammals of the Eocene of Egypt. Geological Magazine, 5:109-115 and 157-162. https://doi.org/10.1017/S001675680012343X

Andrews, C.W. 1906. A Descriptive Catalogue of the Tertiary Vertebrata of the Fayum, Egypt. British Museum of Natural History, London. https://doi.org/10.5962/bhl.title.55134

Argue, D., Groves, C.P., Lee, M.S.Y., and Jungers, W.L. 2017. The affinities of Homo floresiensis based on phylogenetic analyses of cranial, dental, and postcranial characters. Journal of Human Evolution. https://doi.org/10.1016/j.jhevol.2017.02.006

Asher, R.J., Gunnel, G.F., Seiffert, E.R., Pattinson, D., Tabuce, R., Hautier, L., and Sallam, H.M. 2017. Dental eruption and growth in Hyracoidea (Mammalia, Afrotheria). Journal of Vertebrate Paleontology, 37:e1317638. https://doi.org/10.1080/02724634.2017.1317638

Asher, R.J. and Lehmann, T. 2008. Dental eruption in afrotherian mammals. BMC Biology, 6(1):14. https://doi.org/10.1186/1741-7007-6-14

Barry, J.C. 1988. Dissopsalis, a middle and late Miocene proviverrine creodont (Mammalia) from Pakistan and Kenya. Journal of Vertebrate Paleontology, 8:25-45. https://doi.org/10.1080/ 02724634.1988 .10011682

Bastl, K., Morlo, M., Nagel, D., and Heizmann, E. 2011. Differences in the tooth eruption sequence in Hyaenodon ('Creodonta': Mammalia) and implications for the systematics of the genus. Journal of Vertebrate Paleontology, 31:181-192. https://doi.org/10.1080/ 02724634.2011.540052

Bastl, K. and Nagel, D. 2013. First evidence of the tooth eruption sequence of the upper jaw in Hyaenodon (Hyaenodontidae, Mammalia) and new information on the ontogenetic development of its dentition. Paläontologsche Zeitschrift, 88:481-494. https://doi.org/ 10.1007/s12542-013-0207-z

Bastl, K., Nagel, D., and Peigné, S. 2014. Milk tooth morphology of small-sized Hyaenodon (Hyaenodontidae, Mammalia) from the European Oligocene-evidence of a Hyaenodon lineage in Europe. Palaeontographica, Abt A: Palaeozoology-Stratigraphy, 303:61-84. https:/ /doi.org/10.1127/pala/303/2014/61

Beck, R.M.D. and Lee, M.S.Y. 2014. Ancient dates or accelerated rates? Morphological clocks and the antiquity of placental mammals. Proceedings of the Royal Society B: Biological Sciences, 281(1793):20141278. https://doi.org/10.1098/rspb.2014.1278

Binder, W.J. and Van Valkenburgh, B. 2000. Development of bite strength and feeding behaviour in juvenile spotted hyenas (Crocuta crocuta). Journal of Zoology, 252:273-283. https:doi.org/ 10.1111/j.1469-7998.2000.tb00622.x

Binder, W.J. and Van Valkenburgh, B. 2010. A comparison of tooth wear and breakage in Rancho La Brea sabertooth cats and dire wolves across time. Journal of Vertebrate Paleontology, 30:255-261. https://doi.org/10.1080/02724630903413016

Borths, M.R., Holroyd, P.A., and Seiffert, E.R. 2016. Hyainailourinae and Teratodontinae cranial material from the late Eocene of Egypt and the application of parsimony and Bayesian methods to the phylogeny and biogeography of Hyaenodonta (Placentalia, Mammalia). PeerJ, 4:e2639. http://doi.org/10.7717/peerj.2639

Borths, M.R. and Seiffert, E.R. 2017. Craniodental and humeral morphology of a new species of Masrasector (Teratodontinae, Hyaenodonta, Placentalia) from the late Eocene of Egypt and locomotor diversity in hyaenodonts. PLOS ONE, 12(4):e0173527. https://doi.org/10.1371/ journal.pone.0173527

Borths, M.R. and Stevens, N.J. 2017. The first hyaenodont form the late Oligocene Nsungewe Formation of Tanzania: insights into the Paleogene-Neogene carnivore transition. PLOS ONE, 12(10):e0185301. https://doi.org/10.1371/journal.pone.0185301

Bryant, H.N. 1988. Delayed eruption of the deciduous upper canine in the sabertoothed carnivore Barbourofelis lovei (Carnivora, Nimravidae). Journal of Vertebrate Paleontology, 8:295-306. https://doi.org/10.1080/02724634.1988.10011712

Bryant, H.N. 1990. Implications of the dental eruption sequence in Barbourofelis (Carnivora, Nimravidae) for the function of upper canines and the duration of parental care in sabretoothed carnivores. Journal of Zoology, 222:585-590. https://doi.org/10.1111/j.14697998.1990.tb06015.x

Chevallier, C., Gauthier, G., and Berteaux, D. 2017. Age estimation of live arctic foxes Vulpes lagopus based on teeth condition. Wildlife Biology, 17:wlb.00304. https://doi.org/10.2981/ wlb.00304 
Ciancio, M.R., Castro, M.C., Galliari, F.C., Carlini, A.A., and Asher, R.J. 2012. Evolutionary implications of dental eruption in Dasypus (Xenarthra). Journal of Mammalian Evolution, 19:1-8. https://doi.org/10.1007/s10914-011-9177-7

Codron, D., Carbone, C., and Clauss, M. 2013. Ecological interactions in dinosaur communities: influences of small offspring and complex ontogenetic life histories. PLOS ONE, 8(10):e77110. https://doi.org/10.1371/journal.pone.0077110

Coutinho, S., Buschang, P.H., and Miranda, F. 1993. Relationships between mandibular canine calcification stages and skeletal maturity. American Journal of Orthodontics and Dentofacial Orthopedics, 104:262-268. https://doi.org/10.1016/S0889-5406(05)81728-7

Crochet, J.-Y., Thomas, H., Roger, J., and Al-Sulaimani, S. 1990. Première découverte d'un créodonte dans la péninsule Arabique: Masrasector ligabuei nov. sp. (Oligocène inférieur de Taqah, Formation d'Ashawq, Sultanat d'Oman). Comptes rendus de l'Académie des sciences, Paris, Série II, 311:1455-1460.

de Queiroz, K. 1985. The ontogenetic method for determining character polarity and its relevance to phylogenetic systematics. Systematic Biology, 34:280-299. https://doi.org/ 10.1093/sysbio/34.3.280

Finarelli, J.A. and Flynn, J.J. 2009. Brain-size evolution and socieality in Carnivora. Proceedings of the National Academy of Sciences, USA, 106:9345-9349. https://doi.org/10.1073/ pnas.0901780106

Fink, W.L. 1982. The conceptual relationship between ontogeny and phylogeny. Paleobiology, 8:254-264. https://doi.org/10.1017/S0094837300006977

Fischer, P. 1880. Note sur un nouveau genre de mammifère fossile (Apterodon gaudryi) des Phosphorites du Quercy. Bulletin de la Société Géologique de France, 8:288-290.

Gorscak, E., O'Connor, P.M., Stevens, N.J., and Roberts, E.M. 2014. The basal titanosaurian Rukwatitan bisepultus (Dinosauria: Sauropoda) from the middle Cretaceous Galula Formation, Rukwa Rift Basin, southwestern Tanzania. Journal of Vertebrate Paleontology, 34:1133-1154. https://doi.org/10.1080/02724634.2014.845568

Goswami, A. and Polly, P.D. 2010. The influence of modularity on cranial morphological disparity in Carnivora and Primates. PLOS ONE, 5(3):e9517. https://doi.org/10.1371/ journal.pone.0009517

Grohé, C., Morlo, M., Chaimanee, Y., Blondel, C., Coster, P., Valentin, X., Salem, M., Bilal, A.A., Jaeger, J.-J., and Brunet, M. 2012. New Apterodontinae (Hyaenodontida) from the Eocene locality of Dur At-Talah (Libya): systematic, paleoecological and phylogenetical implications. PLOS ONE 7(11):e49054. https://doi.org/10.1371/journal.pone.0049054

Halliday, T.J.D., Upchurch, P., and Goswami, A. 2015. Resolving the relationships of Paleocene placental mammals. Biological Reviews, 92:521-550. https://doi.org/10.1111/brv.12242

Henderson, E. 2007. Platyrrhine dental eruption sequences. American Journal of Physical Anthropology, 134:226-239. https://doi.org/10.1002/ajpa.20658

Herrera, J.P. and Dávalos, L.M. 2016. Phylogeny and divergence times of lemurs inferred with recent and ancient fossils in the tree. Systematic Biology, 65:772-791. https://doi.org/ 10.1093/sysbio/syw035

Holroyd, P.A. 1999. New Pterodontinae (Creodonta: Hyaenodontidae) from the late Eoceneearly Oligocene Jebel Qatrani Formation, Fayum Province, Egypt. PaleoBios, 19(2):1-18.

Hone, D.W.E., Farke, A.A., and Wedel, M.J. 2016. Ontogeny and the fossil record: what, if anything, is an adult dinosaur? Biology Letters, 12: 20150947. https://doi.org/10.1098/ rsbl.2015.0947

Hughes, T., Dempsey, P., Richards, L., and Townsend, G. 2000. Genetic analysis of deciduous tooth size in Australian twins. Archives of Oral Biology, 45:997-1004. https://doi.org/10.1016/ S0003-9969(00)00066-2

Hughes, T.E., Bockmann, M.R., Seow, K., Gotjamanos, T., Gully, N., Richards, L.C., and Townsend, G.C. 2007. Strong genetic control of emergence of human primary incisors. Journal of Dental Research, 86:1160-1165. https://doi.org/10.1177/154405910708601204

Kolb, C., Scheyer, T.M., Veitschegger, K., Forasiepi, A.M., Amson, E., van der Geer, A.A.E., Van den Hoek Ostende, L.W., Hayashi, S., and Sánchez-Villagra, M.R. 2015. Mammalian bone palaeohistology: a survey and new data with emphasis on island forms. PeerJ, 3:e1358. https://doi.org/10.7717/peerj.1358

Koufos, G.D. and de Bonis, L. 2004. The deciduous lower dentition of Ouranopithecus macedoniensis (Primates, Hominoidea) from the late Miocene deposits of Macedonia, 
Greece. Journal of Human Evolution, 46:699-718. https://doi.org/10.1016/ j.jhevol.2004.03.007

Lange-Badré, B. and Böhme, M. 2005. Apterodon intermedius, sp. nov., a new European creodont mammal from MP22 of Espenhain (Germany). Annals de Paléontologie, 91:311328. https://doi.org/10.1016/j.annpal.2005.08.001

Lavrov, A.V. 2007. A new species of Paroxyaena (Hyaenodontidae, Creodonta) from Phosphorites of Quercy, Late Eocene, France. Paleontological Journal, 41:298-311. https:// doi.org/10.1134/S0031030107040144

Lee, M.S.Y. and Worthy, T.H. 2012. Likelihood reinstates Archaeopteryx as a primitive bird. Biology Letters, 8:299-303. https://doi.org/10.1098/rsbl.2011.0884

Lewis, M.E. and Morlo, M. 2010. Creodonta, p. 543-560. In Werdelin, L. and Sanders, W. (eds.), Cenozoic Mammals of Africa. University of California Press, Berkely.

Lindström, J. 1999. Early development and fitness in birds and mammals. Trends in Ecology and Evolution, 14:343-348. https://doi.org/10.1016/S0169-5347(99)01639-0

Linnaeus, C. 1758. Systema Naturae per regna tria naturae, secundum classes, ordines, genera, species, cum characteribus, differentiis, synonymis, locis. Editio decima, reformata. Holmiae: Laurentius Salvius. https://doi.org/10.5962/bhl.title.542

Lund, E.K., O'Connor, P.M., Loewen, M.A., and Jinnah, Z.A. 2016. A new centrosaurine ceratopsid, Machairoceratops cronusi gen et sp. nov., from the Upper Sand Member of the Wahweap Formation (Middle Campanian), Southern Utah. PLoS ONE, 11(5):e0154403. https://doi.org/10.1371/journal.pone.0154403

Meachen-Samuels, J.A. and Binder, W.J. 2010. Sexual dimorphism and ontogenetic growth in the American lion and sabertoothed cat from Rancho La Brea. Journal of Zoology, 280:271279. https://doi.org/10.1111/j.1469-7998.2009.00659.x

Mellett, J.S. 1977. Paleobiology of North American Hyaenodon (Mammalia, Creodonta). Contributions to Vertebrate Evolution, 1:1-134.

Miles, A.E.W. and Grigson, C. 1990. Colyer's Variations and Diseases of the Teeth of Animals. Cambridge University Press, Cambridge, UK.

Miller, E.R., Gunnell, G.F., Seiffert, E.R., Sallam, H., and Schwartz, G.T. 2017. Patterns of dental emergence in early anthropoid primates from the Fayum Depression, Egypt. Historical Biology, 1-9. https://doi.org/10.1080/08912963.2017.1294169

Monson, T.A. and Hlusko, L.J. 2016. The evolution of dental eruption sequence in artiodactyls. Journal of Mammalian Evolution. https://doi.org/10.1007/s10914-016-9362-9

Morales, J., Brewer, P., and Pickford, M. 2010. Carnivores (Creodonta and Carnivora) from the basal middle Miocene of Gebel Zelten, Libya, with a note on a large amphicyonid from the middle Miocene of Ngorora, Kenya. Bulletin of the Tethys Geological Society, Cairo, 5:43-54.

Morales, J., Pickford, M., Fraile, S., Salesa, M.J., and Soria, D. 2007. New carnivoran material (Creodonta, Carnivora and Incertae sedis) from the early Miocene of Napak, Uganda. Paleontological Research, 11:71-84. https://doi.org/10.2517/13428144(2007)11[71:NCMCCA]2.0.CO;2

Morlo, M. and Habersetzer, J. 1999. The Hyaenodontidae (Creodonta, Mammalia) from the lower middle Eocene (MP 11) of Messel (Germany) with special remarks on new x-ray methods. Courier Forschungsinstitut Senckenberg, 216:31-73.

Morlo, M., Miller, E.R., and El-Barkooky, A.N. 2007. Creodonta and Carnivora from Wadi Moghra, Egypt. Journal of Vertebrate Paleontology, 27:145-159. https://doi.org/10.1671/ 0272-4634(2007)27[145:CACFWM]2.0.CO;2

O'Leary, M.A., Bloch, J.I., Flynn, J.J., Gaudin, T.J., Giallombardo, A., Giannini, N.P., Goldberg, S.L., Kraatz, B.P., Luo. Z.-X., Meng, J., Ni, X., Novacek, M.J., Perini, F.A., Randall, Z.S., Rougier, G.W., Sargis, E.J., Silcox, M.T., Simmons, N.B., Spaulding, M., Velazco, P.M., Weksler, M., Wible, J.R., and Cirranello, A.L. 2013. The placental mammal ancestor and the post-K-Pg radiation of placentals. Science, 339:662-667. https://doi.org/10.1126/ science. 1229237

Osborn H.F. 1909. New carnivorous mammals from the Fayum Oligocene, Egypt. Bulletin of the American Museum of Natural History, 26:415-424. http://hdl.handle.net/2246/1452

Peterkova, R., Lesot, H., and Peterka, M. 2006. Phylogenetic memory of developing mammalian dentition. Journal of Experimental Biology (Molecular and Developmental Evolution), 306B:234-250. https://doi.org/10.1002/jez.b.21093

Pilgrim, G.E. 1910. Notices of new mammalian genera and species from the Tertiaries of India. Records of the Geological Survey of India, 40:63-71. 
Pilgrim, G.E. 1932. The fossil Carnivora of India. Memoirs of the Geological Survey of India. Palaeontologica Indica, 18:1-232. https://doi.org/10.1017/S0016756800096448

Polly, P.D. 1996. The skeleton of Gazinocyon vulpeculus gen. et comb. nov. and the cladistic relationships of Hyaenodontidae (Eutheria, Mammalia). Journal of Vertebrate Paleontology, 16:303-319. https://doi.org/10.1080/02724634.1996.10011318

Rager, L., Hautier, L., Forasiepi, A., Goswami, A., and Sánchez-Villagra, M. R. 2013. Timing of cranial suture closure in placental mammals: phylogenetic patterns, intraspecific variation, and comparison with marsupials. Journal of Morphology, 275:125-140. https://doi.org/ 10.1002/jmor.20203

Rana, R., Kumar, K., Zack, S., Solé, F., Rose, K., Missiaen, K.P., Singh, L., Sahni, A., and Smith, T. 2015. Craniodental and postcranial morphology of Indohyaenodon raoi from the early Eocene of India, and its implications for ecology, phylogeny, and biogeography of hyaenodontid mammals. Journal of Vertebrate Paleontology. 35:e965308. https://doi.org/ 10.1080/02724634.2015.965308

Ronquist, F., Teslenko, M., van der Mark, P., Ayres, D.L., Darling, A., Höhna, S., Larget, B., Liu, L., Suchard, M.A., and Huelsenbeck, J.P. 2012. MrBayes 3.2: efficient Bayesian phylogenetic inference and model choice across a large model space. Systematic Biology, 61:539-542. https://doi.org/10.1093/sysbio/sys029

Rose, K. 2006. The Beginning of the Age of Mammals. Johns Hopkins University Press, Baltimore.

Ross, C. 1996. Adaptive explanation for the origins of the Anthropoidea (Primates). American Journal of Primatology, 40:205-230. https://doi.org/10.1002/(SICl)10982345(1996)40:3<205::AID-AJP1>3.0.CO;2-1

Sallam, H.M. and Seiffert, E.R. 2016. New phiomorph rodents form the latest Eocene of Egypt, and the impact of Bayesian "clock"-based phylogenetic methods on estimates of basal hystricognath relationships and biochronology. PeerJ, 4:e1717. https://doi.org/10.7717/ peerj.1717

Sánchez-Villagra, M.R. 2010a. Developmental palaeontology in synapsids: the fossil record of ontogeny in mammals and their closest relatives. 20092005 Proceedings of the Royal Society B. https://doi.org/10.1098/rspb.2009.2005

Sánchez-Villagra, M.R. 2010b. Suture closure as a paradigm to study late growth in recent and fossil mammals: a case study with giant deer and dwarf deer skulls. Journal of Vertebrate Paleontology, 30:1895-1898. https://doi.org/10.1080/02724634.2010.521218

Savage, R.J.G. 1965. Fossil mammals of Africa 19: the Miocene Carnivora of East Africa. Bulletin of the British Museum of Natural History (Geology), 10:239-316. http:// direct.biostor.org/reference/118744

Schlosser, M. 1910. Über einige fossil saügetiere aus dem Oligocän von Ägypten. Zoologischer Anzeiger, 35:500-508. https://biodiversitylibrary.org/page/9741941

Schneider, C.A., Rasband, W.S., and Eliceiri, K.W. 2012. NIH Image to ImageJ: 25 years of image analysis. Nature Methods, 9:671-675. https://doi.org/10.1038/nmeth.2089

Shubin, N.H., Daeschler, E.B., and Jenkins, F.A. 2006. The pectoral fin of Tiktaalik roseae and the origin of the tetrapod limb. Nature, 440:764-771. https://doi.org/10.1038/nature04637

Simons, E.L. and Gingerich, P.D. 1974. New carnivorous mammals from the Oligocene of Egypt. Annals of the Geological Survey of Egypt, 4:157-166.

Slaughter, B.H., Pine, R.H., and Pine, N.E. 1974. Eruption of cheek teeth in Insectivora and Carnivora. Journal of Mammalogy, 55:115-125. https://doi.org/10.2307/1379261

Smith, B.H. 1989. Dental development as a measure of life history in primates. Evolution, 43:683-688. https://doi.org/10.1111/j.1558-5646.1989.tb04266.x

Smith, B.H. 2000. Schultz's rule and the evolution of tooth emergence and replacement patterns in primates and ungulates, p. 212-217. In Teaford, M.F., Smith, M.M., and Ferguson, M.W.J. (eds.), Development, Function and Evolution of Teeth. Cambridge University Press, Cambridge, U.K.

Smuts, G.L., Anderson, J.L, and Austin, J.C. 1978. Age determination of the African lion (Panthera leo). Journal of Zoology, 185:115-146. https://doi.org/10.1111/j.14697998.1978.tb03317.x

Solé, F., Amson, E., Borths, M., Vidalenc, D., Morlo, M., and Bastl, K. 2015. A new large hyainailourine from the Bartonian of Europe and its bearings on the evolution and ecology of massive hyaenodonts (Mammalia). PLoS ONE 10(10):e0141941. https://doi.org/10.1371/ journal.pone.0135698 
Solé, F., Essid, E.M., Marzougui, W., Temani, R., Ammar, H.K., Mahboubi, M., Marivaux, L., Vianey-Liaud, M., and Tabuce, R. 2016. New fossils of Hyaenodonta (Mammalia) from the Eocene localities of Chambi (Tunisia) and Bir el Ater (Algeria), and the evolution of the earliest African hyaenodonts. Palaeontologia Electronica, 19.3.41A:1-23. https://doi.org/ $10.26879 / 598$ palaeo-electronica.org/content/2016/1598-new-eocene-african-hyaenodonts

Solé, F., Gheerbrant, E., and Godinot, M. 2011. New data on the Oxyaenidae from the Early Eocene of Europe; biostratigraphic, paleobiogeographic and paleoecologic implications. Palaeontologia Electronica, 14.2.13A:1-41. palaeo-electronica.org/2011_2/258/index.html

Solé, F., Lhuillier, J., Adaci, M., Bensalah, M., Mahboubi. M., and Tabuce, R. 2014. The hyaenodontidans from the Gour Lazib area (?early Eocene, Algeria): implications concerning the systematics and the origin of the Hyainailourinae and Teratodontinae. Journal of Systematic Paleontology, 12:303-322. https://doi.org/10.1080/14772019.2013.795196

Spaulding, M., O'Leary, M.A., and Gatesy, J. 2009. Relationships of Cetacea (Artiodactyla) among mammals: increased taxon sampling alters interpretations of key fossils and character evolution. PLoS ONE, 4(9):e7062. https://doi.org/10.1371/journal.pone.0007062

Stern, J.T. and Susman, R.L. 1983. The locomotor anatomy of Australopithecus afarensis. American Journal of Physical Anthropology, 60:279-317. https://doi.org/10.1002/ ajpa.1330600302

Szalay, F.S. 1967. The affinities of Apterodon (Mammalia, Deltatheridia, Hyaenodontidae). American Museum Novitates, 2293:1-17. http://hdl.handle.net/2246/3088

Townsend, G., Bockmann, M., Hughes, T., and Brook, A. 2012. Genetic, environmental and epigenetic influences on variation in human tooth number, size and shape. Odontology, 100:1-9. https://doi.org/10.1007/s10266-011-0052-z

Tseng, Z.J., Grohé, C., and Flynn, J.J. 2016. A unique feeding strategy of the extinct mammal Koloponomuos: convergence on sabretooths and sea otters. Proceedings of the Royal Society B, 283(1826). https://doi.org/10.1098/rspb.2016.0044

Turner, A.H., Pritchard, A.C., and Matzke, N.J. 2017. Empirical and Bayesian approaches to fossil-only divergence times: a study across three reptile clades. PLOS ONE, 12(2):e0169885. https://doi.org/10.1371/journal.pone.0169885

Uhen, M.D. 2000. Replacement of deciduous first premolars and dental eruption in archaeocete whales. Journal of Mammalogy, 81:123-133. https://doi.org/10.1644/15451542(2000)081<0123:RODFPA>2.0.CO;2

Urdy, S., Wilson, L.A.B. Haug, J.T., and Sánchez-Villagra, M.R. 2013. On the unique perspective of paleontology in the study of developmental evolution and biases. Biological Theory, 8:293. https://doi.org/10.1007/s13752-013-0115-1

Van Valen, L. 1967. New Paleocene insectivores and insectivore classification. Bulletin of the American Museum of Natural History, 135:217-284. http://hdl.handle.net/2246/358

Van Valkenburgh, B. 1988. Incidence of tooth breakage among large, predatory mammals. The American Naturalist, 131:291-302. https://doi.org/10.1086/284790

Van Valkenburgh, B. 2007. Déjà vu: the evolution of feeding morphologies in the Carnivora. Integrative and Comparative Biology, 47:147-163. https://doi.org/10.1093/icb/icm016

Veitschegger, K. and Sánchez-Villagra, M.R. 2016. Tooth eruption sequences in cervids and the effect of morphology, life history, and phylogeny. Journal of Mammalian Evolution, 23:251263. https://doi.org/10.1007/s10914-015-9315-8

White, P.A. and Belant, J.L. 2016. Individual variation in dental characteristics for estimating age of African lions. Wildlife Biology, 22:71-77. https://doi.org/10.2981/wlb.00180

Zack, S.P. 2011. New species of the rare early Eocene creodont Galecyon and the radiation of the early Hyaenodontidae. Journal of Paleontology, 85:315-336. https://doi.org/10.1666/10093.1

Zack, S.P. 2012. Deciduous dentition of Didymictis (Carnivoramorpha: Viverravidae): implications for the first appearance of "Creodonta." Journal of Mammalogy. 93:808-817. https://doi.org/10.1644/11-MAMM-A-245.1 


\section{APPENDIX 1.}

Character-taxon matrix used in this study, formatted for the program Mesquite (mesquiteproject.org). See palaeo-electronica.org/content/2017/2056-deciduous-hyaenodont-teeth for zipped file of appendix PDFs.

\section{APPENDIX 2.}

Descriptions of the characters used in this analysis with the source of the character or comparable characters from other analyses. See palaeo-electronica.org/content/2017/2056-deciduoushyaenodont-teeth for zipped file of appendix PDFs.

\section{APPENDIX 3.}

List of all the taxa and specimens used in this analysis, along with information on age and locality data. See palaeo-electronica.org/content/2017/2056-deciduous-hyaenodont-teeth for zipped file of appendix PDFs.

\section{APPENDIX 4.}

Input file for the Bayesian phylogenetic analysis, formatted for MrBayes (mrbayes.sourceforge.net). See palaeo-electronica.org/content/2017/2056-deciduous-hyaenodont-teeth for zipped file of appendix PDFs.

\section{APPENDIX 5.}

Consensus "allcompat" (majority-rule plus compatible groups) tree from Bayesian phylogenetic analysis. See palaeo-electronica.org/content/2017/2056-deciduous-hyaenodont-teeth for zipped file of appendix PDFs. 